\title{
South Africa's newly approved marine protected areas have increased the protected modelled habitat of nine odontocete species
}

\author{
Jean Purdon ${ }^{1, *}$, Fannie Shabangu ${ }^{2}$, Marc Pienaar $^{3}$, Michael J. Somers ${ }^{4}$, \\ Ken P. Findlay ${ }^{5}$ \\ ${ }^{1}$ Whale Unit, Mammal Research Institute, Department of Zoology and Entomology, University of Pretoria, Pretoria 0002, South Africa \\ ${ }^{2}$ Fisheries Management Branch, Department of Environmental Affairs, Cape Town 8000, South Africa \\ ${ }^{3}$ South African Environmental Observation Network, uLwazi Node, Pretoria 0083, South Africa \\ ${ }^{4}$ Eugène Marais Chair of Wildlife Management, Centre for Invasion Biology, Mammal Research Institute, University of Pretoria, \\ Pretoria 0002, South Africa \\ ${ }^{5}$ CPUT Research Chair: Oceans Economy, Cape Peninsula University of Technology, Cape Town 8000, South Africa
}

\begin{abstract}
Marine protected areas (MPAs) are important for the preservation of ecosystem functioning, ecosystem services, resilience and biodiversity around the world. In South Africa, the role of MPAs in the protection of cetaceans is poorly understood, a knowledge gap that may affect management decisions and future cetacean conservation. Here, we used presence data of 9 odontocete species (namely southern bottlenose whale Hyperoodon planifrons, common dolphin Delphinus delphis, dusky dolphin Lagenorhynchus obscurus, false killer whale Pseudorca crassidens, Indo-Pacific humpback dolphin Sousa chinensis, Heaviside's dolphin Cephalorhynchus heavisidii, killer whale Orcinus orca, Risso's dolphin Grampus griseus and Indo-Pacific bottlenose dolphin Tursiops aduncus) to predict their distribution in the South African exclusive economic zone (EEZ) using ensemble models. The data were collected from various opportunistic, historical and scientific records spanning the period 1957-2014. Up to 9 predictor variables (sea surface temperature, chlorophyll a concentration, salinity, bathymetry, distance to shore, bottom slope, eastward and northward sea water velocity and bioregion) were used in the ensemble model to predict the distributions for each odontocete species. Model results suggest that some of the species' preferred habitats are partially (i.e. $<5 \%$ of the distribution) protected by the established MPAs, but the protection area does increase with the recently approved MPAs. This study pro-
\end{abstract}

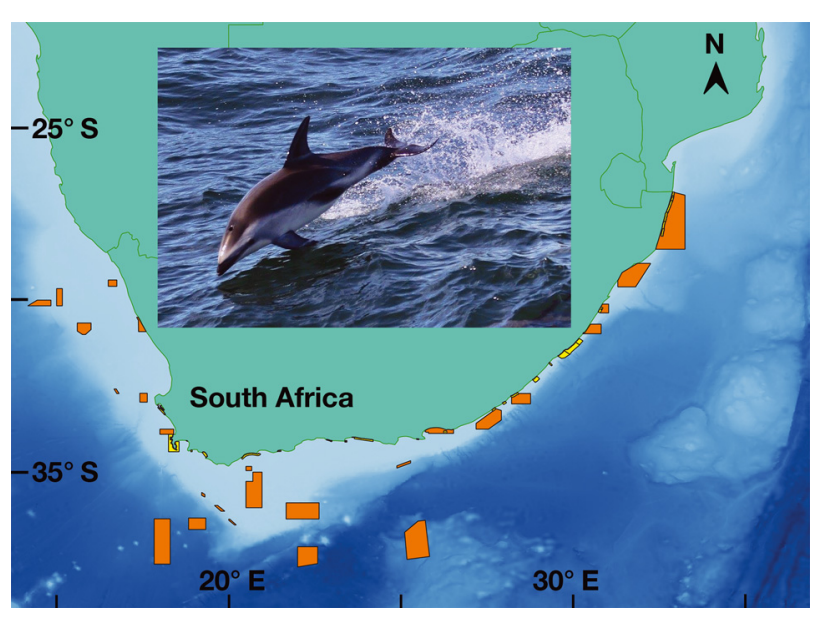

South Africa's new (orange) marine protected areas (MPA) (previously established MPAs yellow) increase the protection of the marine ecosystem, including nine odontocete species. Image \& photo: Jean Purdon

vides a baseline for the distribution of the 9 odontocete species in relation to the MPAs, which could facilitate the protection and management of these species in the region and help identify important marine mammal areas.

KEY WORDS: Habitat modelling - Species distributions - Marine protected areas . Odontocetes . South Africa 


\section{INTRODUCTION}

Countries with coastlines are introducing new legislation to increase the numbers and sizes of marine protected areas (MPAs) to reduce biodiversity loss and conserve ecosystem functioning (Edgar et al. 2014, Roberts et al. 2018). The Convention on Biological Diversity (CBD), through decision X/2 (reinstituted in 2010), set out 20 Aichi biodiversity targets to reduce biodiversity loss in the marine and terrestrial environments (CBD 2010, 2012, Pereira et al. 2013, Edgar et al. 2014, Thomas et al. 2014, Roberts et al. 2018). Notably, Aichi target number 11 encourages member states to increase representative MPAs to a total of $10 \%$ of their Exclusive Economic Zone (EEZ) by 2020 (Thomas et al. 2014).

'Operation Phakisa' is a South African government initiative to fast-track the delivery of the 2030 National Development Plan by unlocking the oceans' economy (van Wyk 2015, Findlay 2018). South Africa, a member state of the $\mathrm{CBD}$, until recently protected less than $0.4 \%$ of its EEZ, encompassing only $60 \%$ of habitat variability (Sink 2016). To meet the objectives of 'Operation Phakisa' and the Aichi targets, a network of new MPAs covering 46 of the 54 recognised habitats was proposed in 2016 (Sink 2016), increasing the total protection to $5 \%$ of South Africa's EEZ (Harris et al. 2011, RSA 2016, Sink 2016). Of these MPAs, 2 have recently (RSA 2016) been dropped and there are now 18 new MPAs, plus an expansion of 2 existing MPAs approved by cabinet (RSA 2019). This new MPA network aims to maintain a sustainable ocean economy (Harris et al. 2011, Sink 2016).

An ecosystem-based management approach-a balance between social, ecological and governance at the relevant temporal and spatial scales, using scientific knowledge and effective monitoring to attain resource sustainability (Long et al. 2015) — combined with the MPA network is important for safeguarding the oceans' environmental integrity. Not all marine faunal habitats were considered under the newly approved MPAs (Sink 2016) and this is especially true for cetaceans. Only 1 of the established MPAs, the Walker Bay Whale Sanctuary, was promulgated to protect cetaceans (RSA 2001). MPAs for cetaceans are usually designed around habitats that are critical to their survival, for example breeding, feeding and migratory areas (Hoyt 2012). As these critical habitats are typically large, protecting them as safe havens for charismatic cetaceans would create an umbrella effect, simultaneously protecting a multitude of other species and habitat types (Hoyt 2012). However, protecting large areas and multiple habitat types is difficult and impractical. Therefore, in order to conserve biodiversity, MPAs should be a starting point in which careful design, connectivity and zonation aid in an ecosystem-based management approach (Agardy et al. 2011, Hoyt 2012).

In South Africa, certain laws and policies support the protection of cetaceans (e.g. RSA 1994, 1998). For example, existing law dictates that before any activity is conducted that could result in environmental degradation, an environmental impact assessment (EIA) must be undertaken to develop an environmental management plan (EMP; RSA 2014, 2015). Ideally, these EIAs should rely on the best available and most up-to-date science. Critical habitat identification and distribution data are often limited, resulting in poorly developed EIAs (Nowacek et al. 2013). This is most obvious when considering cetaceans, as there is a paucity of current literature on the odontocete distribution in the South African EEZ (Findlay 1989, Findlay et al. 1992, Best 2007).

Distribution modelling is one way in which the identification of species distributions can aid in developing an EMP (Forney et al. 2012, Hoyt 2012, Stock \& Micheli 2016). Distribution modelling of rare species or data-deficient species, such as cetaceans, remains problematic, as the combination of many environmental variables and a low number of presence data requires many assumptions which can lead to extrapolation bias due to model over-fitting (Breiner et al. 2015). Current practice, especially in such instances, is to use an ensemble of models to overcome some of the uncertainty of a single-model approach (Coetzee et al. 2009, Thuiller et al. 2009, Zanardo et al. 2017).

Here we used 5 separate algorithms to predict the distribution of 9 commonly encountered odontocete species in the South African EEZ and identify the environmental niche factors that best predict their distribution. These species include: southern bottlenose whale Hyperoodon planifrons, common dolphin Delphinus delphis, dusky dolphin Lagenorhynchus obscurus, false killer whale Pseudorca crassidens, Indo-Pacific humpback dolphin Sousa chinensis, Heaviside's dolphin Cephalorhynchus heavisidii, killer whale Orcinus orca, Risso's dolphin Grampus griseus and Indo-Pacific bottlenose dolphin Tursiops aduncus. We evaluated each algorithm and the ensemble model using 2 methods: the area under the receiver operating characteristic curve (AUC) and the true skill statistic (TSS). Finally, we aimed to approximate the percentage of odontocete habitat that is protected through the established and recently approved MPAs within South Africa's EEZ. 


\section{MATERIALS AND METHODS}

\subsection{Study area}

The study site (Fig. 1) encompasses the South African EEZ in its entirety, including both the existing and the newly approved MPAs (RSA 2016). These MPAs are under the jurisdiction of South African law, meaning South Africa can regulate anthropogenic activities.

\subsection{Species presence data}

We collated presence data of 9 odontocete species from several opportunistic, historical and scientific records, spanning all seasons from 1957-2014 (see Table S1 in Supplement 1 and Fig. S1 in Supplement 2 at www.int-res.com/articles/suppl/m633p001_supp/). The majority $(54 \%)$ of data are from citizen scientists and were collected and collated by Nan Rice (CEO of Dolphin Action and Protection Group, Fish Hoek),

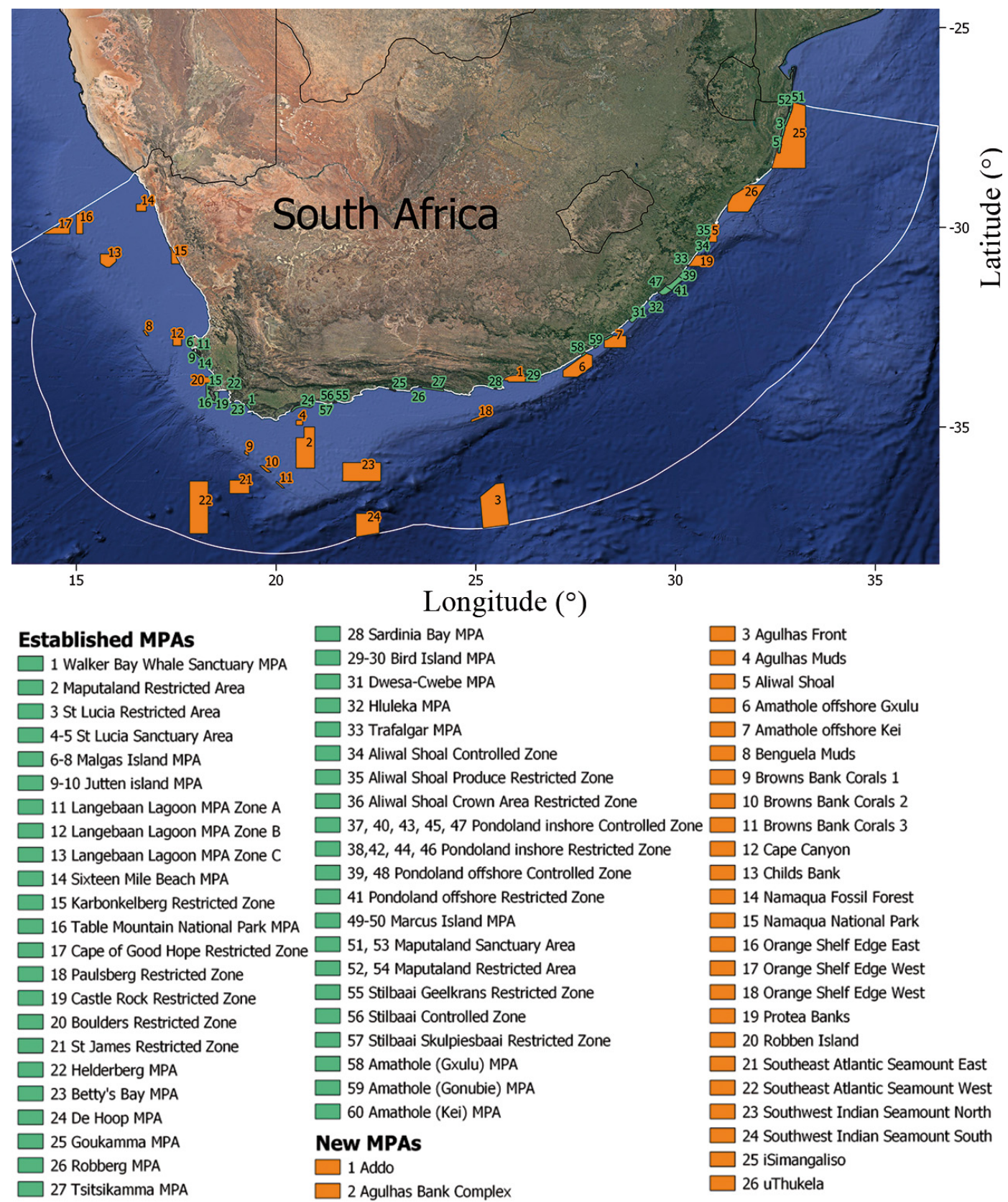

Fig. 1. South African exclusive economic zone study area (surrounded by a white line). Orange blocks signify the recently approved marine protected areas (MPAs), and the green blocks signify the established MPAs 
Table 1. Oceanographic and topographic environmental variables used in the ensemble modelling process. MARSPEC: Marine Spatial Ecology; SMI: Standard Mapped Image; MGET: Marine Geospatial Ecology Tools; AVHRR: Advanced Very High Resolution Radiometer; SANBGIS: South African Biodiversity Geographic Information System; SANBI: South African National Biodiversity Institute. Date refers to the date of calculated monthly averages. na: not applicable

\begin{tabular}{|c|c|c|c|c|c|}
\hline $\begin{array}{l}\text { Environmental } \\
\text { variable }\end{array}$ & $\begin{array}{l}\text { Spatial } \\
\text { resolution }\end{array}$ & Source & Units & Date & Reference \\
\hline Bathymetry & $30 \operatorname{arc}-\sec (\sim 1 \mathrm{~km})$ & MARSPEC & $\mathrm{m}$ & na & Sbrocco \& Barber (2013) \\
\hline Slope & $30 \operatorname{arc}-\sec (\sim 1 \mathrm{~km})$ & MARSPEC & Degrees & na & Sbrocco \& Barber (2013) \\
\hline $\begin{array}{l}\text { Distance to } \\
\text { shore }\end{array}$ & $30 \operatorname{arc}-\sec (\sim 1 \mathrm{~km})$ & MARSPEC & $\mathrm{km}$ & na & Sbrocco \& Barber (2013) \\
\hline $\begin{array}{l}\text { Chlorophyll a } \\
\text { (chl a) }\end{array}$ & $4 \mathrm{~km}$ & $\begin{array}{l}\text { Copernicus- } \\
\text { OCEANCOLOUR_GLO_CHL_L4 } \\
\text { _REP_OBSERVATIONS_009_082 }\end{array}$ & $\mathrm{mg} \mathrm{m}^{-3}$ & $2002-2016$ & Volpe et al. (2019) \\
\hline $\begin{array}{l}\text { Sea surface } \\
\text { temperature } \\
\text { (SST) }\end{array}$ & $0.083^{\circ}(\sim 8 \mathrm{~km})$ & $\begin{array}{l}\text { Copernicus- } \\
\text { GLOBAL_REANALYSIS_PHY } \\
\text { _001_030 }\end{array}$ & ${ }^{\circ} \mathrm{C}$ & $\begin{array}{c}1991-2016 \\
(2018)\end{array}$ & Fernandez \& Lellouche \\
\hline Salinity & $0.083^{\circ}(\sim 8 \mathrm{~km})$ & $\begin{array}{l}\text { Copernicus- } \\
\text { GLOBAL_REANA } \\
\text { LYSIS_PHY_001_030 }\end{array}$ & $\mathrm{psu}$ & 1991-2016 & $\begin{array}{l}\text { Fernandez \& Lellouche } \\
\text { (2018) }\end{array}$ \\
\hline $\begin{array}{l}\text { Eastwards sea } \\
\text { water velocity } \\
\left(\mathrm{v}_{\mathrm{o}}\right)\end{array}$ & $0.083^{\circ}(\sim 8 \mathrm{~km})$ & $\begin{array}{l}\text { Copernicus- } \\
\text { GLOBAL_REANA } \\
\text { LYSIS_PHY_001_030 }\end{array}$ & $\mathrm{m} \mathrm{s}^{-1}$ & 1991-2016 & $\begin{array}{l}\text { Fernandez \& Lellouche } \\
\text { (2018) }\end{array}$ \\
\hline $\begin{array}{l}\text { Northwards sea } \\
\text { water velocity } \\
\left(\mathrm{u}_{\mathrm{o}}\right)\end{array}$ & $0.083^{\circ}(\sim 8 \mathrm{~km})$ & $\begin{array}{l}\text { Copernicus- } \\
\text { GLOBAL_REANA } \\
\text { LYSIS_PHY_001_030 }\end{array}$ & $\mathrm{m} \mathrm{s}^{-1}$ & 1991-2016 & $\begin{array}{l}\text { Fernandez \& Lellouche } \\
\text { (2018) }\end{array}$ \\
\hline Bioregions & $\begin{array}{l}\text { Rasterised } \\
\text { polygon } 4 \mathrm{~km}\end{array}$ & SANBGIS & $\mathrm{km}$ & na & SANBI (2004) \\
\hline
\end{tabular}

who formed a citizen science network for data collection in South Africa. Historical data (37\% of the data), which are curated by the Mammal Research Institute Whale Unit of the University of Pretoria, consist of records from dedicated aerial and boat-based scientific surveys, aerial historical whaling searches and data collated by Best (2007).

We sourced the final $9 \%$ of the data as follows: $5 \%$ from the Ocean Biogeographic Information System Spatial Ecological Analysis of Megavertebrate Populations (OBIS-SEAMAP (Halpin et al. 2009) and $4 \%$ from the Petroleum Agency of South Africa (PASA). OBIS-SEAMAP (http://seamap.env.duke.edu) is an online platform of archived data, supplied by a growing number of individuals and institutions for research into the ecology and management of marine vertebrates (Halpin et al. 2009). The data obtained from PASA were collected by marine mammal observers and passive acoustic monitors, who are required by the EMP to ensure the mitigation of marine seismic survey impacts on marine mammal fauna (RSA 2015). We checked all data for authenticity and accuracy by weighting records according to known species ranges and observers' descriptions of the species. Permission to use the data was obtained from all of the named sources (Table S1).

\subsection{Environmental data}

We considered 9 environmental predictors for modelling the distribution of cetaceans in the South African EEZ (Fig. S2 in Supplement 2). These were selected based on known or potential relationships with cetaceans (Redfern et al. 2006, Torres et al. 2013). These variables are described in Table 1 and comprise 5 oceanographic predictors: sea surface temperature (SST), salinity, chlorophyll a (chl a) concentration, eastwards $\left(\mathrm{u}_{\mathrm{o}}\right)$ and northwards $\left(\mathrm{v}_{\mathrm{o}}\right)$ sea water velocity (Fig. S2); and 3 topographical predictors: bathymetry, distance to shore and slope (Fig. S2). The final environmental predictor was the bioregions of the South African EEZ (Fig. S3 in Supplement 2).

Previous studies have shown that topographic variables (Torres et al. 2013) and habitat types (Zanardo et al. 2017), here bioregions, are reliable indicators for predicting cetacean distributions. Bioregions were defined by faunal, floral and physical characteristics (Lombard et al. 2004, Griffiths et al. 2010). The bioregions of the South African EEZ included Atlantic offshore bioregion, Namaqua bioregion, South-western Cape bioregion, Agulhas bioregion, Indo-Pacific bioregion, West Indian offshore bioregion, Natal bioregion, Delagoa bioregion and the South-west Indian 
offshore bioregion (Lombard 2004, Griffiths et al. 2010). The bioregion polygons (WGS84, EPSG 4326) were rasterised to a $0.083^{\circ}(\sim 8 \mathrm{~km})$ geographic grid using ArcMap (ESRI 2011) for the predictive modelling process.

We chose SST, salinity and chl a concentration, as these are known indicators for phytoplankton biomass (Sbrocco \& Barber 2013, Pennino et al. 2017), and northwards and eastwards sea water velocities, as they can indicate the movement of plankton (McQuaid 2010). These indicators were used as proxies for cetacean food availability (Sbrocco \& Barber 2013, Pennino et al. 2017). Data for SST, salinity, $u_{o}$ and $v_{0}$ were available from December 1991 to December 2016, while chl a data were available from January 2002 to December 2016. The majority of the sightings of odontocetes were recorded from the 1970 s and late 1990s, with some presence data recorded as early as 1957. Other studies have indicated that averaging oceanographic data over several years provides sufficient data to model predicted species distribution (e.g. Torres et al. 2013). To conduct the distribution modelling, the monthly SST, salinity, chl $a_{1} \mathrm{u}_{\mathrm{o}}$ and $\mathrm{v}_{\mathrm{o}}$ data were first averaged (at their native spatial resolution and projection) into mean yearly values, then re-projected to a standard WGS84, EPSG 4326 geographic projection in ArcMap.

To ensure that all variables had the same spatial resolution and extent, we resampled them to a $0.083^{\circ}$ $(\sim 8 \mathrm{~km})$ grid using nearest interpolation in the data management tool of ArcMap. They were then clipped to the study area extent $\left(y_{\max }=-26.8, y_{\min }=\right.$ -38.2, $x_{\min }=13.3, x_{\max }=36.6$; Fig. 1) using the 'raster' package (Hijmans 2015) in R, version 3.6.1 (R Core Team 2019). Finally, to determine if there was multi- collinearity between the environmental predictors, the variance inflation factor (VIF) was tested using the 'car' package (Fox \& Weisberg 2011) in R. High VIF numbers, above 10, indicated that the variation shown by one variable can be explained by the other environmental factors. Therefore, if a value of 10 or higher was obtained, that variable was removed from the models and the VIF test was computed again to ensure no correlation between the rest of the environmental factors (O'Brien 2007).

\subsection{Species distribution modelling}

Distributions of 9 odontocete species in the South African EEZ were modelled using an ensemble approach, where results from 5 individual algorithms were combined. The 5 algorithms used are generalised boosting model (GBM; Elith et al. 2008); classification tree analysis (CTA; De'ath \& Fabricius 2000); flexible discriminant analysis (FDA; Hastie et al. 1994); random forest ( $\mathrm{RF}_{\text {; }}$ Cutler et al. 2007); and surface range envelope ( $S R E ;$ Thuiller et al. 2005). The ensemble model combined these algorithms using the 'BIOMOD2' package (Thuiller et al. 2009) in R. These 5 algorithms out of a possible 11 were chosen because, after testing sample data, they were less likely to overfit and more likely to converge when presence points were low in numbers, and studies by Coetzee et al. (2009) and Barbet-Massin et al. (2012) indicate that these algorithms perform well.

In order to create an ensemble model, however, both presence and absence data are required. Our data consisted of a combination of presence-only data (part of the data set from the Mammal Research Insti-

Table 2. Final ensemble model scores for both model evaluation methods and the parameters used to create them. The figure within the brackets denotes if the numbers of pseudo-absence points chosen was equal to the presence points (=) or 10 times the presence points $(\times 10)$. Environmental variables are described in Table 1. AUC: area under the receiver operating characteristic curve; TSS: true skill statistic

\begin{tabular}{|c|c|c|c|c|}
\hline Species & AUC & TSS & $\begin{array}{l}\text { No. of pseudo- } \\
\text { absence points }\end{array}$ & Environmental variables \\
\hline $\begin{array}{l}\text { Southern bottlenose } \\
\text { whale }\end{array}$ & 0.998 & 0.943 & $161(=)$ & Bioregions, bathymetry, slope, distance to shore, $\mathrm{v}_{0}, \mathrm{SST}$, chl a \\
\hline Common dolphin & 0.995 & 0.925 & $883(=)$ & Bioregions, bathymetry, slope, distance to shore, $\mathrm{v}_{\mathrm{o}}, \mathrm{u}_{\mathrm{o}}$, SST, salinity, chl $a$ \\
\hline Dusky dolphin & 0.999 & 0.977 & $144(=)$ & Bioregions, bathymetry, slope, $\mathrm{v}_{\mathrm{o}}, \mathrm{u}_{\mathrm{o}}, \mathrm{SST}$, salinity, chl a \\
\hline False killer whale & 0.996 & 0.973 & $22(\times 10)$ & Bioregions, bathymetry, slope, $\mathrm{u}_{\mathrm{o}}$, salinity, chl a \\
\hline $\begin{array}{l}\text { Indo-Pacific humpback } \\
\text { dolphin }\end{array}$ & 0.999 & 0.993 & $25(\times 10)$ & Bathymetry, slope, distance to shore, $\mathrm{u}_{\mathrm{o}}, \mathrm{SST}$, chl $a$ \\
\hline Heaviside's dolphin & 1.000 & 0.989 & $628(=)$ & Bioregions, bathymetry, slope, distance to shore, $\mathrm{v}_{0}, \mathrm{u}_{0}$, $\mathrm{SST}$, salinity, chl $a$ \\
\hline Killer whale & 0.993 & 0.922 & $140(=)$ & Bioregions, bathymetry, slope, distance to shore, $\mathrm{v}_{\mathrm{o}}, \mathrm{SST}$, salinity, chl a \\
\hline Risso's dolphin & 0.993 & 0.930 & $156(=)$ & Bioregions, bathymetry, slope, distance to shore, $\mathrm{u}_{0}, \mathrm{SST}$, salinity, chl a \\
\hline $\begin{array}{l}\text { Indo-Pacific bottlenose } \\
\text { dolphin }\end{array}$ & 0.999 & 0.992 & $58(\times 10)$ & Bioregions, bathymetry, slope, distance to shore, $\mathrm{v}_{0}, \mathrm{SST}$ \\
\hline
\end{tabular}


tute [MRI] Whale Unit incidental sightings and the OBIS data set) (Table S1) and some presence-absence data (part of the MRI data set and the Marine Mammal Observer [MMO] and Passive Acoustic Monitor [PAM] data set). Several studies have described the limitations of using presence-only data and suggested possible ways in which to overcome these limitations (e.g. Phillips et al. 2009, Wisz \& Guisan 2009, BarbetMassin et al. 2012, Senay, Worner \& Ikeda 2013). Barbet-Massin et al. (2012), for instance, found that different methods of pseudo-absence selection were appropriate for different types of algorithms and the number of presence points available. We adopted this approach, and test-fitted randomly sampled pseudoabsence points within an environmental envelope in BIOMOD2. The number of pseudo-absence points tested ranged from an equal number to the presence points, 10 times the number of presence points (Table 2) and $2 \%$ of the study area (1440 pseudo-absence points) as suggested for these algorithms by BarbetMassin et al. (2012). The number of pseudo-absence points that resulted in ensemble models with the highest accuracy score and the most plausible predictive distribution maps (according to the known literature, e.g. Findlay et al. 1992, Best 2007) were selected (Kadmon et al. 2004, Barbet-Massin et al. 2012).

Once we had chosen the final number of pseudoabsences for each species, we sub-sampled the pseudo-absence data 10 times and performed a 10fold cross-validation for each sub-sample, using an $80 \%$ split for testing and a $20 \%$ split for training. Overall, there were 100 fits for each of the 9 odontocete species, creating a robust predictive distribution model. The most influential environmental variables were characterised in BIOMOD2 using a random independent technique, providing direct correlation between the algorithms. This technique uses Pearson's correlation between the current variable, which has been randomly permutated, and the values fitted (Thuiller et al. 2009). A variable with a score close to 1 indicates that it had the most influence on the model.

We evaluated the individual algorithms using 2 model evaluation methods available in BIOMOD2: AUC and TSS. We chose these 2 over Cohen's K (kappa), as the kappa statistic has been criticised by several studies (e.g. Allouche et al. 2006) for being severely dependent on occurrence, resulting in biases and statistical artefacts of accuracy estimation (Allouche et al. 2006). AUC and TSS were chosen as they are independent of occurrence. Scores ranged from 0 to 1 , with scores below 0.5 indicating that the model performed worse than random. We conducted a 1-way ANOVA on data that were assumed to be normally distributed for each species. This was done to determine if there was a significant difference between the 2 model evaluation methods and to determine if there was a significant difference between individual algorithms for each model evaluation method. We hypothesised that there would be a significant difference between model evaluation methods and also between the algorithms for each model evaluation method. If there was a significant difference between the algorithms for each evaluation method, Tukey's post hoc test was done to determine which algorithms performed best.

We selected the individual algorithms that produced AUC and TSS scores of $>0.7$ to create the final ensemble model. We then projected the ensemble models onto maps to provide scenarios of the predicted habitat for the 9 odontocete species based on the TSS model evaluation method. Predicted preferred habitat scores ranged from 0 to 1 , with scores closer to 1 indicating a higher probability of predicted occurrence.

\subsection{MPAs}

From the established and newly approved MPAs, we estimated, for each species, how much habitat is protected based on the final ensemble model prediction. To approximate the percentage of protected area for each species, we re-projected and resampled the predicted distribution maps from a WGS84 geographic projection to a custom $5 \mathrm{~km}$ Albers equal area projection in ArcMap using 'project raster' in the data management tool. The likelihood of predicted odontocete occurrence at 0.90 or above (i.e. $90 \%$ or higher) was then calculated for each species using a raster mask with areas at a level of $0.9(90 \%)$ predicted occurrence equal to 1 and the rest equal to 0 in QGIS (QGIS Development Team 2018). Percentage area was obtained using zonal statistics to calculate the sum of all pixels in the approved and established MPAs overlapping with the predicted distribution of each odontocete species at a $90 \%$ level or higher. We used block statistics, where the number of pixels was multiplied by the area of each pixel $\left(25 \mathrm{~km}^{2}\right)$ to obtain total area protected by the MPAs. The percentage area was determined as the ratio between the total area protected by the MPAs and the total area of each odontocete species at a predicted level of $90 \%$ or higher. We downloaded the established MPAs from the South African National Biodiversity Institute website (SANBI 2011) and then manually constructed the recently approved MPA polygons from the relevant Government Gazette notices (RSA 2019). 


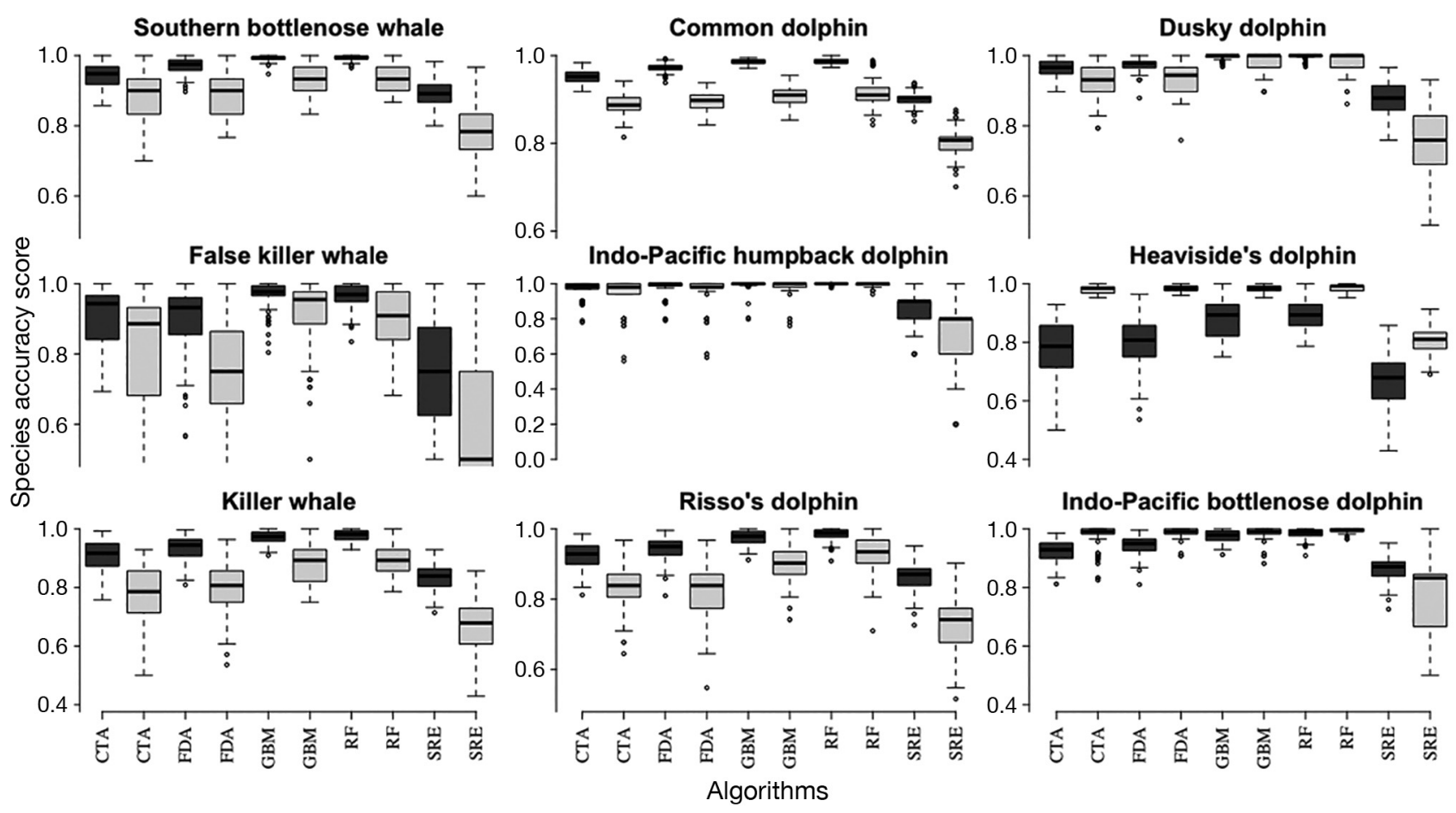

Fig. 2. Comparison of area under the receiver operating characteristic curve (AUC; dark grey) and true skill statistic (TSS; light grey) model evaluation scores between different algorithms used for 9 odontocete species (see Section 2.4 for full algorithm names). AUC and TSS values above 0.5 indicate that the algorithms performed better than random. The horizontal line represents the median value, the shaded boxes represent $50 \%$ of the scores in the middle (inter-quartile range), and the whiskers indicate the scores that are outside the $50 \%$ range. The dots represent outliers (more or less than $3 / 2$ times the upper and lower quartile)

\section{RESULTS}

\subsection{Model performance output}

The final ensemble model scores were all higher than 0.93 for both AUC and TSS evaluation methods (Table 2). Overall, the ensemble model scores were higher or similar to the best performing algorithm, with the AUC scores higher than the TSS scores
(Table 2). The final parameters used to produce the ensemble model are shown in Table 2, which indicates that not all environmental variables were retained owing to high VIF values and because the majority of pseudo-absence points chosen were equal to the number of presence points. This varied slightly as certain combinations gave better results, resulting in the pseudo-absence selection increasing to 10 times the number of presence points (Table 2).

Table 3. ANOVA results when determining the significance between the model evaluation scores when all algorithms were combined, the significance between algorithms for the true skill statistic (TSS) scores and the significance between algorithms for the area under the receiver operating characteristic curve (AUC) scores. All p-values for algorithms using TSS and AUC were significant $(p<0.0001)$ except for Indo-Pacific bottlenose dolphin where there was no significant difference $(p=0.119)$

\begin{tabular}{|c|c|c|c|c|c|c|}
\hline \multirow[t]{2}{*}{ Species } & \multicolumn{2}{|c|}{ Model evaluation score } & \multicolumn{2}{|c|}{ Algorithms using TSS scores } & \multicolumn{2}{|c|}{ Algorithms using AUC scores } \\
\hline & df & $F$ & df & $F$ & df & $F$ \\
\hline Southern bottlenose whale & 1, 1098 & 346 & 4,545 & 135 & 4,545 & 297 \\
\hline Common dolphin & 1,1098 & 972 & 4,545 & 360 & 4,545 & 1118 \\
\hline Dusky dolphin & 1,1098 & 88 & 4,545 & 377 & 4,545 & 442 \\
\hline False killer whale & 1,1096 & 133 & 4,544 & 100 & 4,544 & 110 \\
\hline Indo-Pacific humpback dolphin & 1,1096 & 37 & 4,544 & 158 & 4,544 & 158 \\
\hline Heaviside's dolphin & 1,1098 & 608 & 4,545 & 1453 & 4,545 & 146 \\
\hline Killer whale & 1,1098 & 458 & 4,545 & 146 & 4,545 & 269 \\
\hline Risso's dolphin & 1,1098 & 402 & 4,545 & 155 & 4,545 & 267 \\
\hline Indo-Pacific bottlenose dolphin & 1,1098 & 3 & 4,545 & 244 & 4,545 & 267 \\
\hline
\end{tabular}


Each algorithm had average AUC and TSS scores that were higher than 0.5 for all 9 species of odontocetes (Fig. 2). The AUC scores for 7 species (southern bottlenose whale, common dolphin, dusky dolphin, false killer whale, Indo-Pacific humpback dolphin, killer whale and Risso's dolphin) were significantly higher than the TSS scores $(\mathrm{p}<0.0001$; see ANOVA results for each species in Table 3), while for Heaviside's dolphin, AUC scores were significantly lower than the TSS scores $\left(p=1.74 \times 10^{-9}\right.$, see ANOVA results for each species in Table 3 ). For Indo-Pacific bottlenose dolphin there was no significant difference between AUC and TSS scores ( $\mathrm{p}=$ 0.119). These results confirm our hypothesis for the 1-way ANOVA, indicating that there was a significant difference between the 2 methods of model evaluation. On average, AUC and TSS followed asimilar trend with regards to best and worst performing algorithms for each modelled species (Fig. 2). When looking at both the AUC and TSS scores, the RF algorithms performed the best for all species, except false killer whales, for which GBM was the best performing algorithm (Fig. 2). Oneway ANOVA results for each species indicated that our hypotheses were accepted, as there was a significant difference between the algorithms in the 2 model evaluation methods $(p<0.0001$; see ANOVA results for each species in Table 3). Tukey's post hoc tests indicated which algorithms performed significantly better (Figs. S4 \& S5 in Supplement 2). There were only slight differences between the predicted distributions for the 2 methods of model evaluation, so only the TSS-predicted distribution maps for each species are displayed (Fig. 3).

The coefficient of variance for all species was predominantly below 0.25 (Fig. 4), indicating that the models agree with the predictions (Navarro-Cerrillo et al. 2017). There are a few patches where the coefficient of variance for dusky dolphins, Risso's dolphins, killer whales and Southern bottlenose whales are higher than 0.25 but still lower than 0.50 , again indicating that the models performed well according to predictions. For Indo-Pacific bottlenose dolphins up along the west coast and small patches along the east coast, the coefficient of variance is as high as 0.75. For Indo-Pacific humpback dolphins, there are patches where the coefficient of variance is as high as 0.50 (Fig. 4). These results suggest that for these 2 species, the models did not agree with the predictions.

Environmental variables predicting odontocete distributions varied according to species and algorithm type (Table 4). Topographic variables for the best performing algorithms, in particular distance to shore, determined the distributions of killer whales and Risso's dolphins. Bathymetry primarily predicted the distribution of Indo-Pacific bottlenose dolphins and Indo-Pacific humpback dolphins (Table 4). The oceanographic variable SST primarily described the distributions of Southern bottlenose whales, dusky dolphins and Heaviside's dolphins. Salinity and chl a

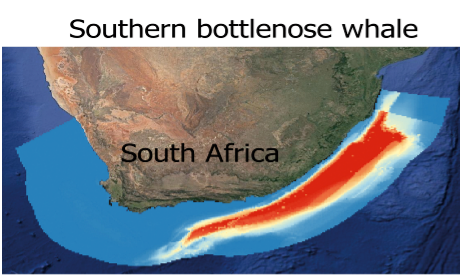

False killer whale

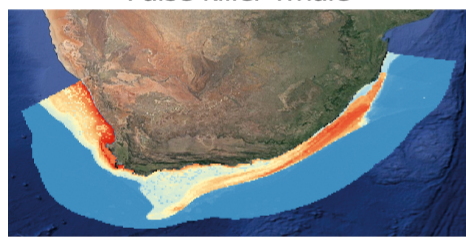

Killer whale

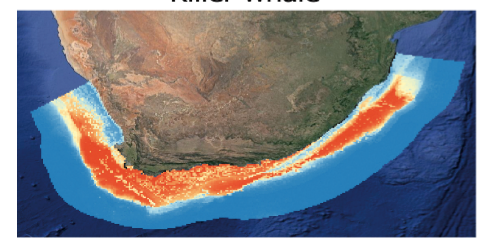

Common dolphin

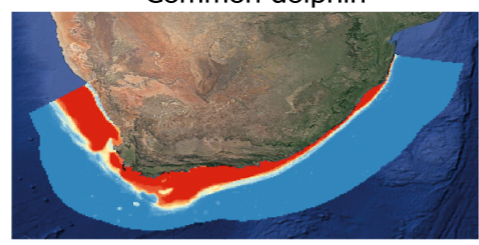

Indo-Pacific humpback dolphin

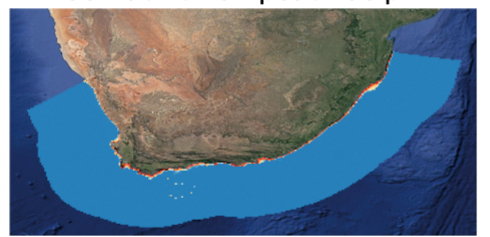

Risso's dolphin

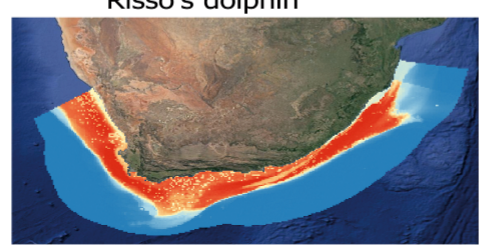

Dusky dolphin

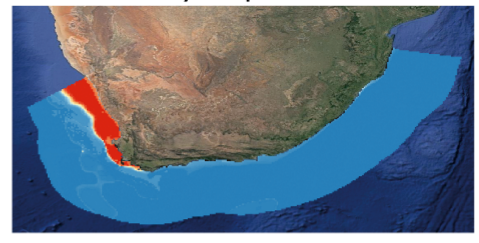

Heaviside's dolphin

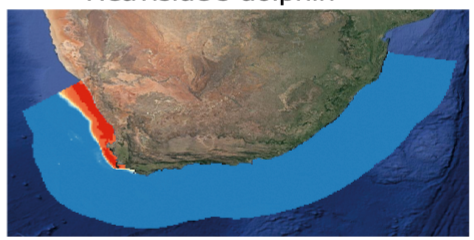

Indo-Pacific bottlenose dolphin

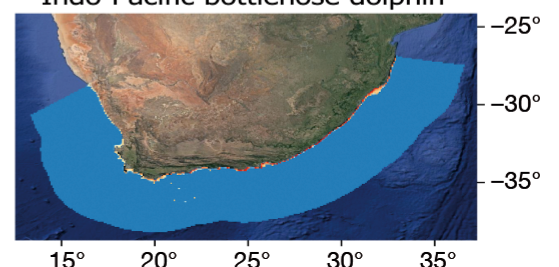

Probability of odontocete occurrence 0 $\square 0.25$ $\square 0.50$ $\square 0.75$ 1

Fig. 3. True skill statistic map projections of predicted distributions for 9 odontocete species. The colour scale represents probability of odontocete occurrence, where red (blue) indicates a high (low) probability of occurrence 


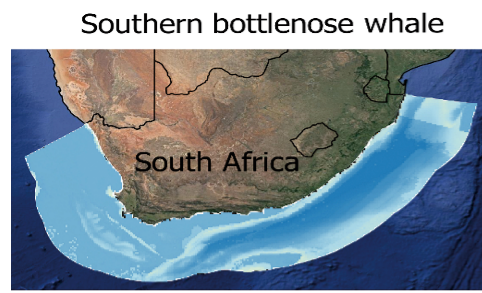

False killer whale

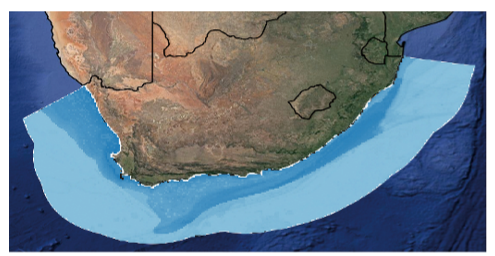

Killer whale

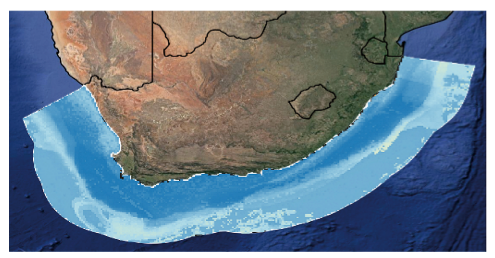

Common dolphin

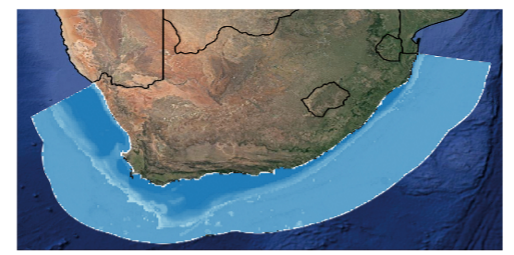

Indo-Pacific humpback dolphin

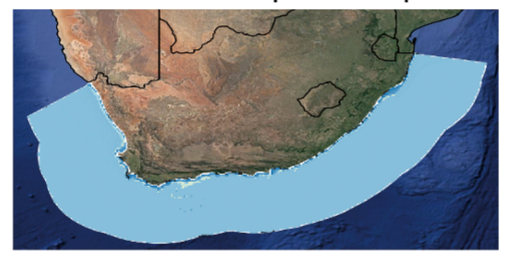

Risso's dolphin

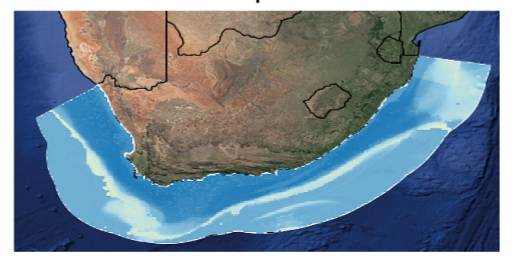

Dusky dolphin

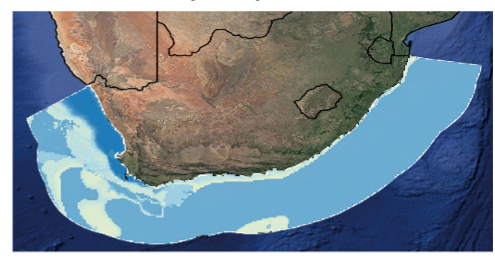

Heaviside's dolphin

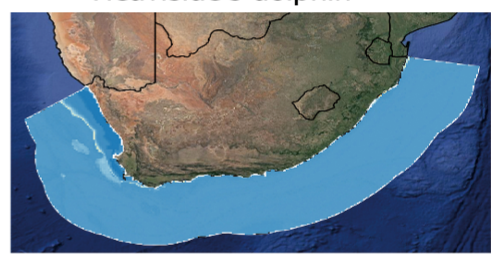

Indo-Pacific bottlenose dolphin

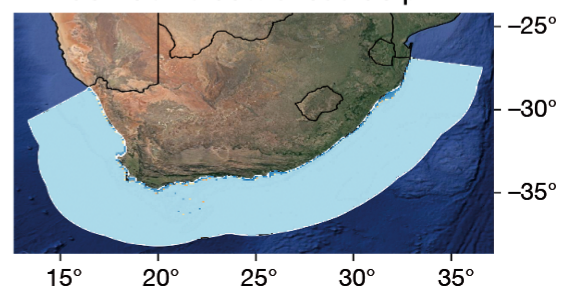

Fig. 4. Coefficient of variance for 9 odontocete species, indicating the extent of data variability in relation to the mean. The variation in relation to the mean is high (low) when the map is red (blue)

described the distributions of false killer whales and common dolphins, respectively (Table 4).

With the exception of Indo-Pacific bottlenose dolphins and Indo-Pacific humpback dolphins, the established MPA network at a level of $90 \%$ protects less than $2 \%$ of predicted habitat occurrence (Figs. 5 $\& 6)$. The level of protection has now increased to more than $5 \%$ with the addition of the recently approved MPAs for common dolphins, false killer whales and Heaviside's dolphins (Fig. 5). A large percentage of predicted habitat is protected for the Indo-Pacific bottlenose dolphins and Indo-Pacific humpback dolphins, as most of the established MPAs in the South African EEZ are in coastal waters off the south and east coasts, overlapping with the narrow coastal distribution of these species. In contrast, for Risso's dolphins, killer whales, dusky dolphins and especially southern bottlenose whales, a very low percentage of habitat is protected in both the established and newly approved MPAs (Figs. $5 \& 6$ ).

\subsection{Southern bottlenose whales}

For all algorithms, SST explained predicted occurrence better than other variables (Table 4). SST, chl a, bathymetry and distance to shore influenced $89 \%$ of the predicted southern bottlenose whale distribution when looking at the best performing algorithm, RF (Table 4). This species was predicted to occur in waters where SST was warmer than $21^{\circ} \mathrm{C}$, chl a concentration was low, distances to shore were less than $250 \mathrm{~km}$, and water depths were less than $700 \mathrm{~m}$ (at a 0.90 level; Fig. 7). This suggests a preference of warmer, less productive offshore waters along South Africa's east and south coasts (Fig. 3). The only MPA that provides a small degree of protection is the iSimangaliso MPA (Figs. 5 \& 6), although it only protects $0.3 \%$ of the southern bottlenose whale habitat where it is predicted to occur at a level of $90 \%$ (Fig. 6).

\subsection{Common dolphins}

Chl $a$ and bathymetry explained 54 and 20\% of predicted occurrence of common dolphins for the best performing algorithm, RF (Table 4). The relative likelihood of occurrence was in areas where the chl a concentration was less than $9 \mathrm{mg} \mathrm{m}^{-3}$ and bathymetry was less than $850 \mathrm{~m}$ deep at a level of 0.90 (Fig. 7). This result indicates that this species is quite cosmopolitan and prevalent around most of South Africa's coastline (Fig. 3). Only 9\% of the common dolphin habitat is protected at a $90 \%$ level of 
Table 4. Percentage of variable importance for 9 odontocete species and algorithms used to create the final ensemble model. Bold indicates the environmental predictor for the best performing algorithm using the true skill statistic (TSS) and area under the receiver operating characteristic curve (AUC) score. Variables are described in Table 1. CTA: classification tree analysis; FDA: flexible discriminant analysis; GBM: generalised boosting model; RF: random forest; SRE: surface range envelope. -: environmental variable was removed due to a high variance inflation factor value

\begin{tabular}{|c|c|c|c|c|c|c|c|c|c|c|}
\hline Species & Model & Bathymetry & Bioregion & $\mathrm{Chl} \mathrm{a}$ & Distance to shore & SST & Slope & Salinity & $\mathrm{u}_{\mathrm{o}}$ & $\mathrm{v}_{\mathrm{o}}$ \\
\hline \multirow{5}{*}{$\begin{array}{l}\text { Southern } \\
\text { bottlenose } \\
\text { whale }\end{array}$} & CTA & 11 & 4 & 17 & 14 & 51 & 0 & - & - & 3 \\
\hline & FDA & 10 & 5 & 8 & 24 & 46 & 0 & - & - & 7 \\
\hline & GBM & 5 & 1 & 22 & 8 & 62 & 0 & - & - & 2 \\
\hline & $\mathbf{R F}$ & 13 & 6 & 25 & 22 & 29 & 0 & - & - & 5 \\
\hline & SRE & 15 & 6 & 20 & 17 & 21 & 4 & - & - & 18 \\
\hline \multirow{5}{*}{$\begin{array}{c}\text { Common } \\
\text { dolphin }\end{array}$} & CTA & 12 & 0 & 81 & 1 & 2 & 0 & 0 & 1 & 4 \\
\hline & FDA & 9 & 0 & 82 & 2 & 3 & 0 & 0 & 1 & 3 \\
\hline & GBM & 22 & 0 & 73 & 1 & 1 & 0 & 1 & 0 & 3 \\
\hline & RF & 20 & $\mathbf{0}$ & 54 & 4 & 6 & 3 & 1 & 5 & 7 \\
\hline & SRE & 20 & 2 & 21 & 17 & 5 & 2 & 17 & 9 & 7 \\
\hline \multirow{5}{*}{$\begin{array}{l}\text { Dusky } \\
\text { dolphin }\end{array}$} & CTA & 0 & 0 & 5 & - & 87 & 0 & 5 & 1 & 1 \\
\hline & FDA & 0 & 0 & 10 & - & 78 & 0 & 10 & 0 & 2 \\
\hline & GBM & 1 & 0 & 22 & - & 10 & 0 & 67 & 0 & 0 \\
\hline & RF & 3 & $\mathbf{0}$ & 20 & - & 49 & 2 & 19 & 2 & $\mathbf{5}$ \\
\hline & SRE & 14 & 6 & 17 & - & 18 & 7 & 14 & 10 & 14 \\
\hline \multirow{5}{*}{$\begin{array}{l}\text { False killer } \\
\text { whale }\end{array}$} & CTA & 2 & 6 & 22 & - & - & 1 & 68 & 1 & - \\
\hline & FDA & 1 & 4 & 24 & - & - & 3 & 67 & 2 & - \\
\hline & GBM & 8 & 7 & 17 & - & - & 1 & 63 & 5 & - \\
\hline & $\mathrm{RF}$ & 9 & 2 & 15 & - & - & 3 & 50 & 21 & - \\
\hline & SRE & 17 & 9 & 21 & - & - & 9 & 35 & 8 & - \\
\hline \multirow{5}{*}{$\begin{array}{l}\text { Indo-Pacific } \\
\text { humpback } \\
\text { dolphin }\end{array}$} & CTA & 60 & - & 0 & 40 & 0 & 0 & - & 0 & - \\
\hline & FDA & 95 & - & 0 & 5 & 0 & 0 & - & 0 & - \\
\hline & GBM & 90 & - & 7 & 1 & 2 & 0 & - & 0 & - \\
\hline & $\mathbf{R F}$ & 62 & - & 2 & 33 & 2 & 1 & - & 1 & - \\
\hline & SRE & 29 & - & 22 & 28 & 3 & 9 & - & 9 & - \\
\hline \multirow{5}{*}{$\begin{array}{l}\text { Heaviside's } \\
\text { dolphin }\end{array}$} & CTA & 0 & 0 & 0 & 0 & 92 & 0 & 8 & 0 & 0 \\
\hline & FDA & 0 & 0 & 0 & 3 & 83 & 0 & 14 & 0 & 0 \\
\hline & GBM & 0 & 0 & 0 & 0 & 0 & 0 & 99 & 0 & 0 \\
\hline & $\mathbf{R F}$ & 0 & 0 & 1 & 1 & 71 & 0 & 27 & 0 & 1 \\
\hline & SRE & 13 & 5 & 15 & 13 & 16 & 4 & 16 & 8 & 10 \\
\hline \multirow{5}{*}{ Killer whale } & CTA & 24 & 2 & 4 & 56 & 2 & 5 & 5 & - & 2 \\
\hline & FDA & 26 & 5 & 6 & 45 & 3 & 8 & 5 & - & 3 \\
\hline & GBM & 16 & 5 & 3 & 45 & 15 & 2 & 10 & - & 3 \\
\hline & RF & 16 & 6 & 8 & 53 & 4 & 6 & 4 & - & 3 \\
\hline & SRE & 21 & 3 & 11 & 25 & 6 & 10 & 16 & - & 8 \\
\hline \multirow{5}{*}{$\begin{array}{l}\text { Risso's } \\
\text { dolphin }\end{array}$} & CTA & 5 & 2 & 15 & 46 & 3 & 1 & 28 & 1 & - \\
\hline & FDA & 8 & 4 & 14 & 37 & 1 & 1 & 35 & 1 & - \\
\hline & GBM & 7 & 3 & 3 & 45 & 12 & 0 & 24 & 4 & - \\
\hline & $\mathbf{R F}$ & 10 & 5 & 12 & 43 & 3 & 3 & 21 & 3 & - \\
\hline & SRE & 20 & 3 & 11 & 22 & 6 & 7 & 23 & 7 & - \\
\hline \multirow{5}{*}{$\begin{array}{l}\text { Indo-Pacific } \\
\text { bottlenose } \\
\text { dolphin }\end{array}$} & CTA & 84 & 0 & - & 16 & 0 & 0 & - & - & 0 \\
\hline & FDA & 88 & 0 & - & 9 & 2 & 0 & - & - & 0 \\
\hline & GBM & 95 & 0 & - & 3 & 1 & 0 & - & - & 0 \\
\hline & $\mathbf{R F}$ & 62 & 1 & - & 32 & 4 & $\mathbf{0}$ & - & - & 1 \\
\hline & SRE & 34 & 2 & - & 33 & 7 & 11 & - & - & 12 \\
\hline
\end{tabular}

predicted occurrence (Fig. 5). Out of all modelled species, common dolphins have the largest area of predicted distribution at a $90 \%$ level (Fig. 6). Because of their large predicted distribution, even though there are a number of MPAs that protect this species, the percentage level of protection remains low (Fig. 6). The largest area where this species is offered protection is from one of the recently approved MPAs, the uThukela MPA, situated along the east coast of South Africa. 


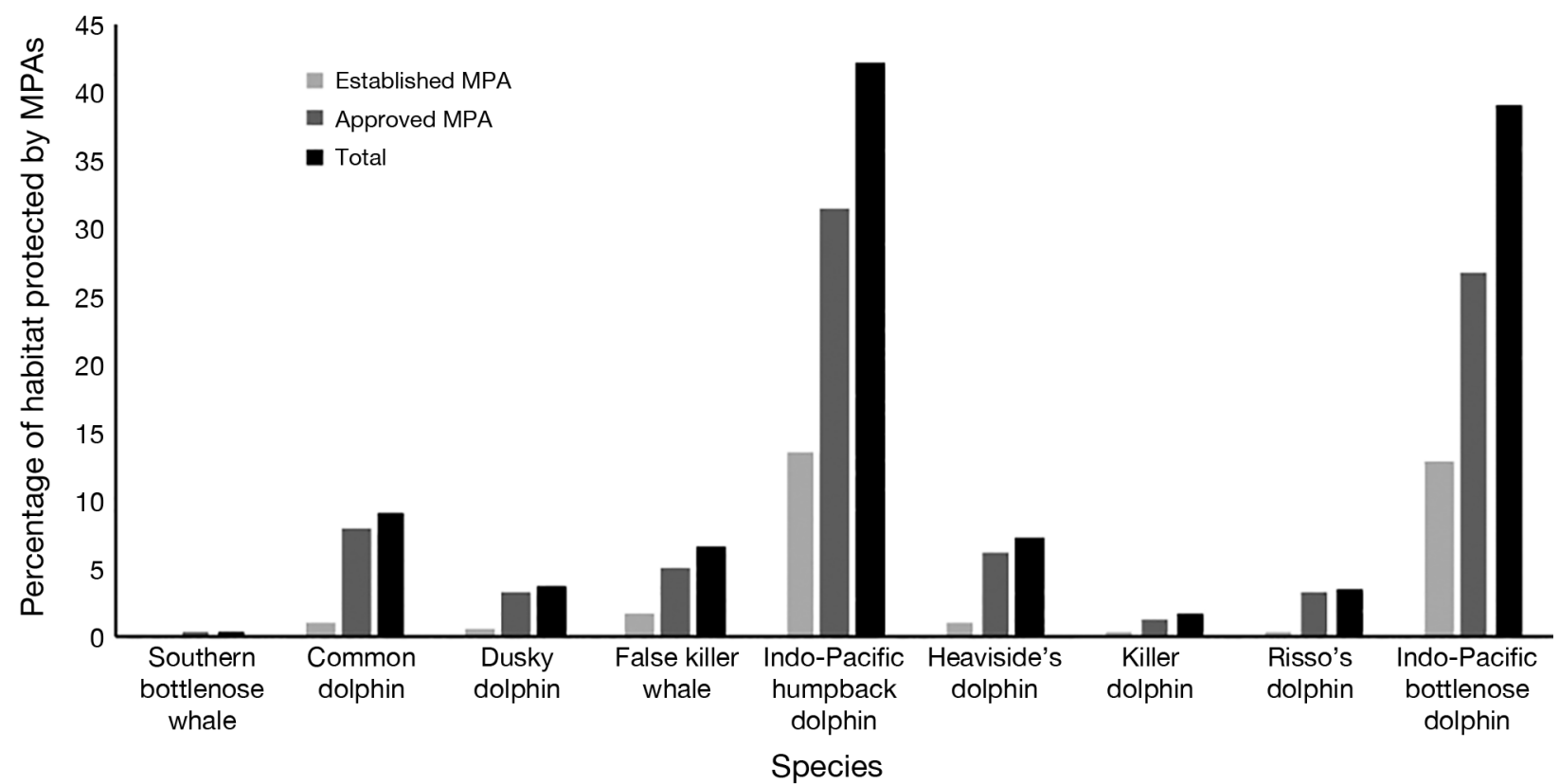

Fig. 5. Percentage of predicted habitat at a $90 \%$ predicted occurrence level protected within South Africa's established, newly approved and total marine protected areas (MPAs) for 9 odontocete species

Southern bottlenose whale

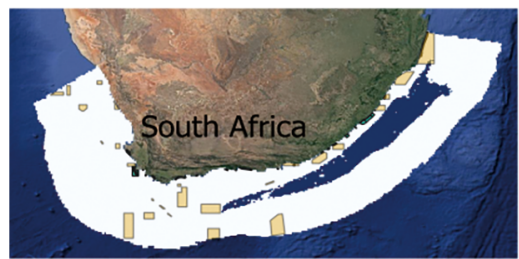

False killer whale

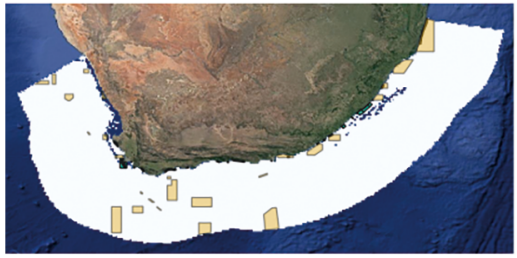

Killer whale

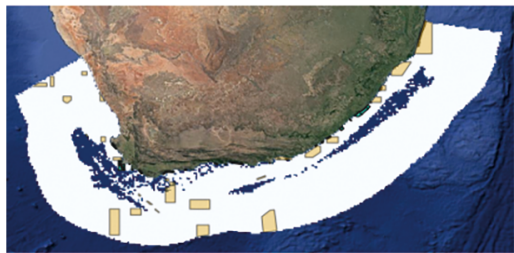

$\square$ Approved MPAs

$\square$ Established MPAs
Common dolphin

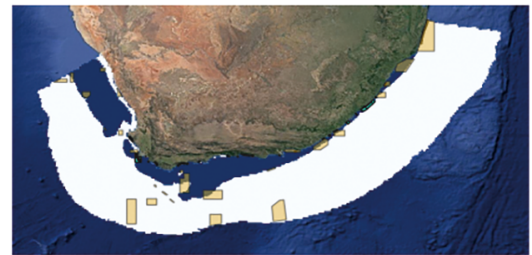

Indo-Pacific humpback dolphin

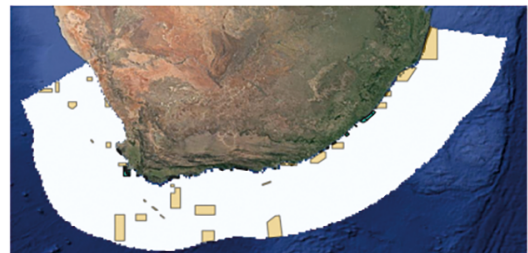

Risso's dolphin

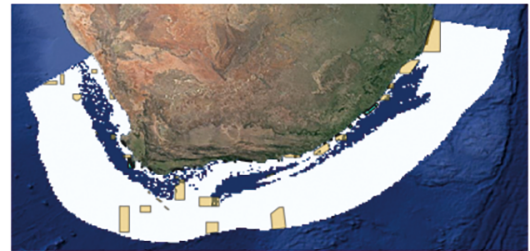

Absent at $90 \%$ level

Present at $90 \%$ level

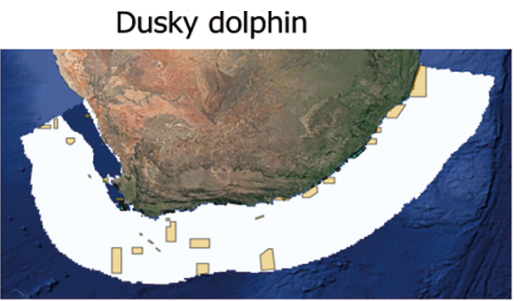

Heaviside's dolphin

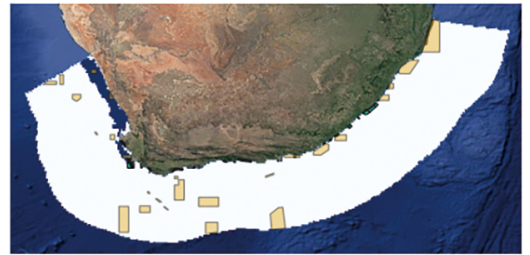

Indo-Pacific bottlenose dolphin

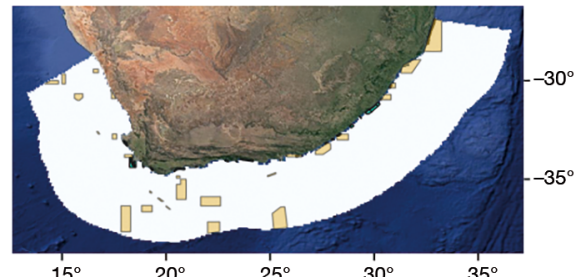

$15^{\circ}$

Fig. 6. Species distributions of 9 odontocete species at a $90 \%$ predicted occurrence level in relation to the established and newly approved marine protected areas (MPAs)

\subsection{Dusky dolphins}

For dusky dolphins, SST had the largest influence on predicted occurrence for all algorithms except
GBM (Table 4). According to the best performing algorithm (RF), SST, chl $a$ and salinity accounted for 49,20 and $19 \%$ of predicted occurrence, respectively (Table 4). Dusky dolphins are more likely to occur in 


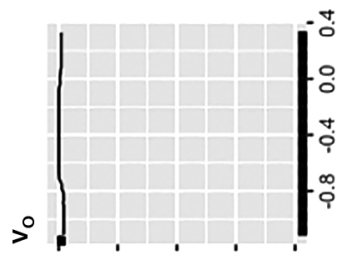

$\stackrel{0}{5}$

竞
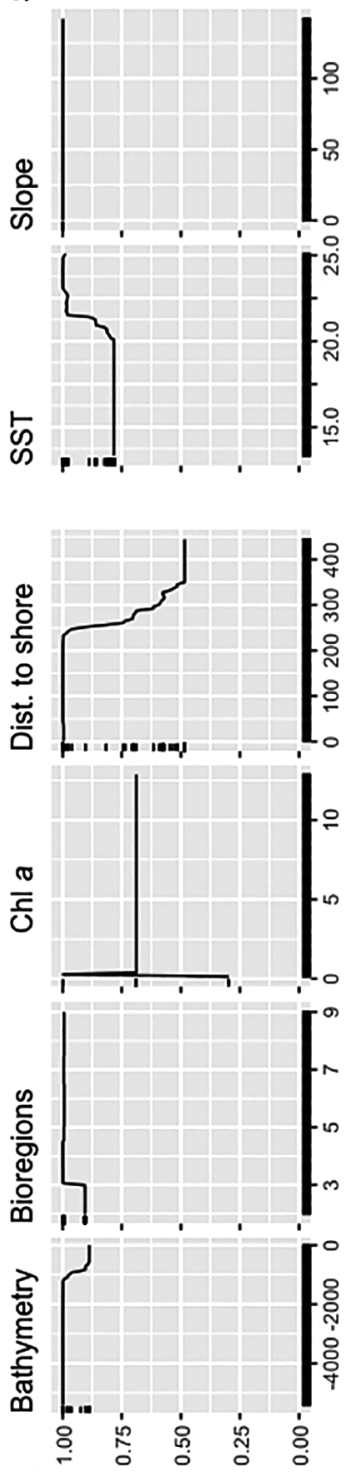

Southern bottlenose whale
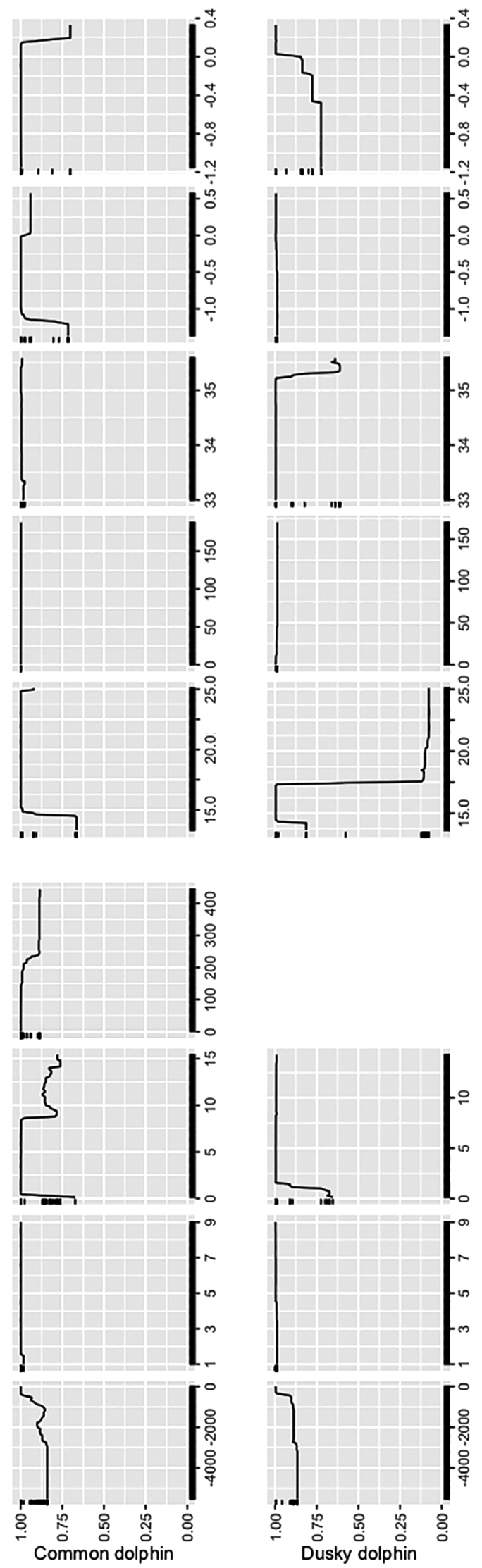

areas where the SST is between 14 and $17^{\circ} \mathrm{C}$, chl a concentrations are $>1 \mathrm{mg} \mathrm{m}^{-3}$, and salinity concentrations are below 35 psu at a 0.90 level (Fig. 7). Dusky dolphins were predicted to occur primarily along the west coast of South Africa, where water temperatures are cooler than along the east coast (Fig. 3). The percentage protection for dusky dolphins increased from 0.6 to $3 \%$ with the recently approved MPAs (Fig. 5). Up until recently, several small coastal MPAs were the only protection dusky dolphins had, but with the addition of the more offshore MPAs, their protection has since increased, mainly from the Namaqua Fossil Forest MPA and the Robben Island MPA (Fig. 6).

\subsection{False killer whales}

Salinity was the most influential variable for the likely occurrence of false killer whales for all algorithms used (Table 4). The best performing algorithm, GBM, indicated that salinity contributed to $63 \%$ of the predicted occurrence, with this species preferring salinity concentrations of $>2 \mathrm{psu}$ at a $90 \%$ level (Fig. 8). Chl a described a further $17 \%$ of occurrence, with false killer whales preferring chl a concen-

Fig. 7. Most influential oceanographic and topographic values according to the best performing algorithms for southern bottlenose whales, common dolphins and dusky dolphins. The $y$-axis indicates the likelihood of occurrence (with 1 being more likely and 0 unlikely) and the $x$-axis indicates the range of the oceanographic or topographical variable. Rug plots indicate the distribution of data for that variable. Bathymetry: depth (m); Bioregions: $0=$ Delgoa, $1=$ West Indian offshore, $2=$ Natal, $3 \& 9=$ South-West Indian offshore, $4=$ Namaqua, $5=$ Atlantic offshore, $6=$ Indo-Pacific offshore, $7=$ Agulhas, 8 = South-western Cape; $\mathrm{Chl}$ a: chlorophyll a concentration $\left(\mathrm{mg} \mathrm{m}^{-3}\right)$; Dist. to shore: distance to shore $(\mathrm{km})$; SST: sea surface temperature $\left({ }^{\circ} \mathrm{C}\right)$; Slope: angle of slope (degrees), Salinity: salinity (psu), $\mathrm{u}_{\mathrm{o}}$ : eastwards sea water velocity $\left(\mathrm{m} \mathrm{s}^{-1}\right) ; \mathrm{v}_{\mathrm{o}}$ : northwards sea water velocity $\left(\mathrm{m} \mathrm{s}^{-1}\right)$ 


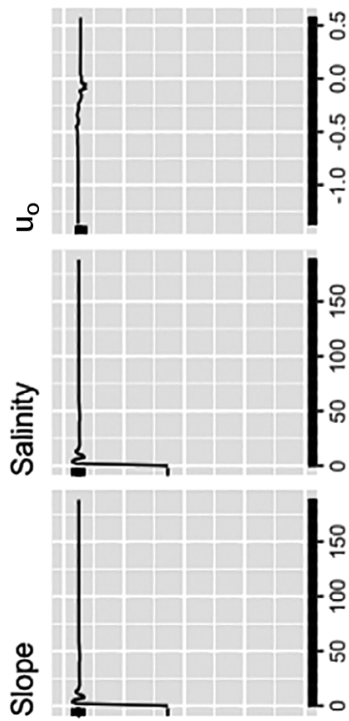

占

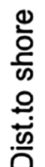
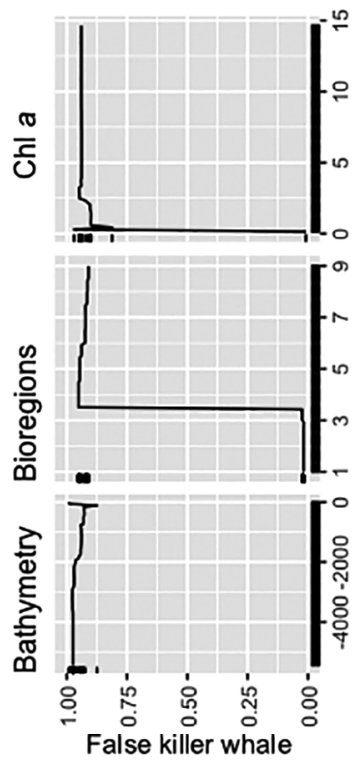
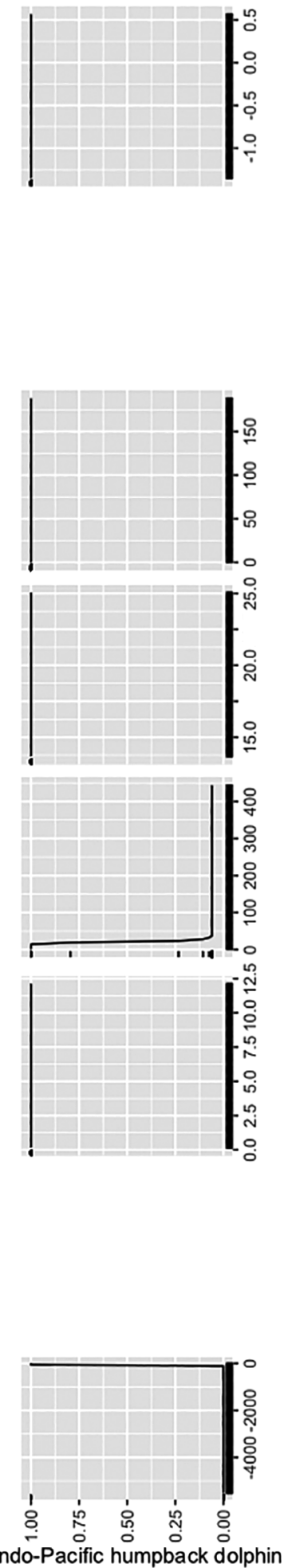
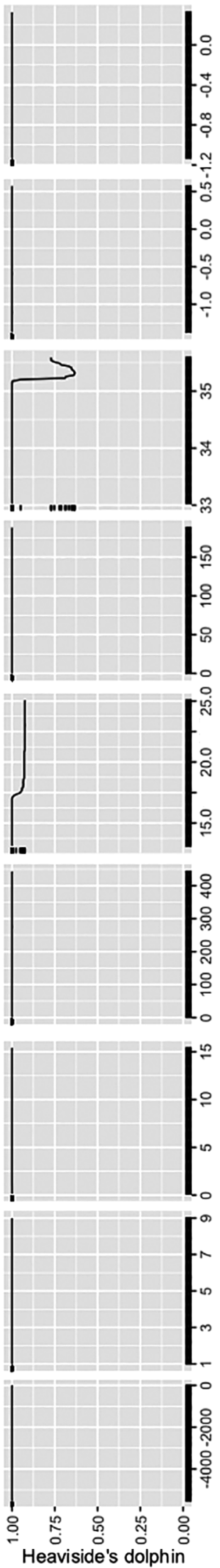

trations of $>1.5 \mathrm{mg} \mathrm{m}^{-3}$ at a 0.90 level (Fig. 8). Predicted distribution, according to Fig. 3, is along the entire South African coastline, with higher levels of prediction on both the west and east coasts, and lower predicted occurrence around the Agulhas Bank (Fig. 3). At a $90 \%$ level of predicted occurrence, false killer whale presence is very low (Fig. 5), with 2 main pockets: one along the west coast and a small one along the east coast of South Africa (Fig. 6). Their level of protection increased from 2 to $7 \%$ with the recently approved MPAs. Most of their habitat is protected by the offshore newly approved Cape Canyon, Namaqua National Park and Robben Island MPAs and one already established MPA, the Table Mountain National Park MPA (Fig. 6).

\subsection{Indo-Pacific humpback dolphins}

For the best performing algorithm, RF (Table 4), bathymetry and distance to shore described 62 and $33 \%$, respectively, of the predicted occurrence of Indo-Pacific humpback dolphins. These dolphins are more likely to occur in waters less than $60 \mathrm{~m}$ deep and at distances less than $15 \mathrm{~km}$ from shore (Fig. 8), and they are likely to occur very close to shore around the South African coastline (Fig. 3). A large percentage $(42 \%)$ of the IndoPacific humpback dolphin habitat is protected by the established and approved MPAs (Fig. 5). This could be related to the very low predicted occurrence of this species at a $90 \%$ level and the fact that it is very coastal, and therefore, protected by the numerous coastal MPAs (Fig. 6).

Fig. 8. Most influential oceanographic and topographic values according to the best performing algorithms for false killer whales, Indo-Pacific humpback dolphins and Heaviside's dolphins. Other details as in Fig. 7 


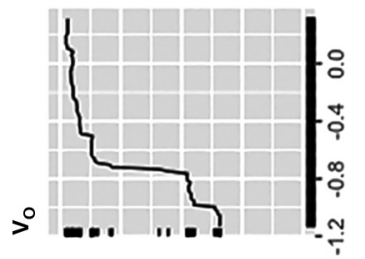

รำ
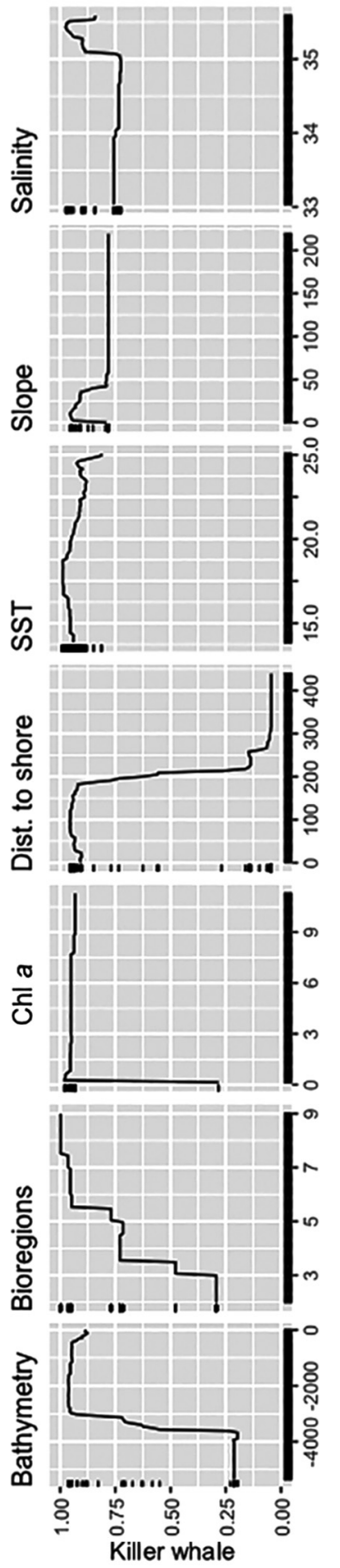
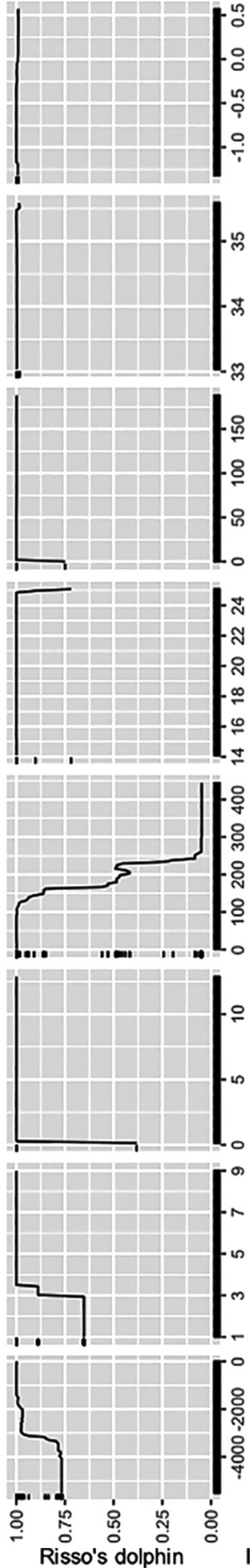
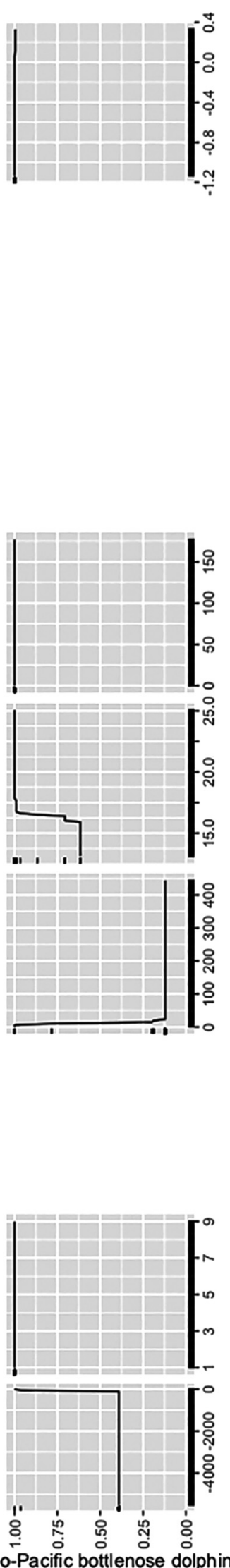

\subsection{Heaviside's dolphins}

SST described $71 \%$ and salinity described $27 \%$ of predicted occurrence of Heaviside's dolphins when looking at the RF algorithm (Table 4). These dolphins prefer cooler temperatures ranging between 13 and $17^{\circ} \mathrm{C}$ and salinity concentrations between 33 and 35 psu at a 0.99 level and higher (Fig. 8). This indicates, as do the predicted distribution maps, that they prefer areas close to shore along the west coast of South Africa (Fig. 3). Their level of protection has recently increased from 1 to $7 \%$ as a few of the newly approved MPAs are located offshore along the west coast (Figs. $5 \& 6$ ). The MPAs that protect the largest proportion of Heaviside's dolphins are the Namaqua Fossil Forest and Robben Island MPAs.

\subsection{Killer whales}

For killer whales, RF was the best performing algorithm, with distance to shore and bathymetry explaining 53 and $16 \%$ of occurrence, respectively (Table 4). Killer whales preferred areas that were less than $180 \mathrm{~km}$ from shore and between depths of 300 and $3000 \mathrm{~m}$ (at a 0.90 level; Fig. 9). The predicted distribution map indicates that they should be prevalent within the half of the South African EEZ that is closer to shore (Fig. 3). The level of protection at a $90 \%$ predicted occurrence increases from less than $1 \%$ to just over $1 \%$ with the addition of the newly approved MPAs (Fig. 5). Most of the killer whale distribution is offshore along the east coast and closer to shore along the west and south coasts, with a rather patchy presence throughout the South African EEZ (Fig. 6). This distribution at a $90 \%$ level has resulted in the low percentage

Fig. 9. Most influential oceanographic and topographic values according to the best performing algorithms for killer whales, Risso's dolphins and Indo-Pacific bottlenose dolphins. Other details as in Fig. 7 
protection from MPAs. The MPA that protects the largest percentage of killer whale habitat is the Agulhas Bank Complex, a newly approved MPA (Fig. 6).

\subsection{Risso's dolphins}

Distance to shore was the most influential variable for Risso's dolphins for 4 out of 5 algorithms (Table 4). The best performing algorithm (RF) indicated that distance to shore and salinity contributed to 43 and $21 \%$ of likely occurrence, respectively (Table 4 ). At a 0.90 level, Risso's dolphins were predicted to prefer waters that were less than $150 \mathrm{~km}$ to shore and at salinity concentrations between 33 and $35 \mathrm{psu}$ (Fig. 9). This reflects the predicted distribution map showing that Risso's dolphins are likely to occur throughout $50 \%$ of the South African EEZ closest to shore (Fig. 3). With the addition of the recently approved MPAs, the protection of Risso's dolphins increases from less than $1 \%$ to just over $3 \%$ (Fig. 5). Risso's dolphins, which have a similar distribution to that of killer whales, are predicted to occur slightly offshore, along the entire coast of South Africa. The MPAs that offer the most protection to the Risso's dolphins have only been recently approved and include the Southwest Indian Seamount South, Amatole offshore Kei and the Agulhas Bank Complex (Fig. 6).

\subsection{Indo-Pacific bottlenose dolphins}

For Indo-Pacific bottlenose dolphins, bathymetry and distance to shore were the most influential variables for all algorithms (Table 4), accounting for 62 and $32 \%$, respectively, of the predicted occurrence for the RF algorithm (Fig. 9). Indo-Pacific bottlenose dolphins were predicted to prefer depths of around $60 \mathrm{~m}$ and distances less than $10 \mathrm{~km}$ from shore. These factors, describing their predicted occurrence, resulted in their preferred habitat being located close to shore within the entire South African EEZ (Fig. 3). Due to the very low numbers of occurrence, at a $90 \%$ predicted level, $39 \%$ of their habitat is protected (Fig. 5). They are also predicted to occur coastally where all of the established MPAs, and many of the newly approved MPAs, are located (Fig. 6).

\section{DISCUSSION}

Our data allowed us to simulate areas with high occurrence of odontocetes and the environmental drivers behind these predicted distributions. The odontocete species showed varying responses to environmental predictors, with some like dusky and Heaviside's dolphins conforming to what is known in the literature (Findlay et al. 1992, Best 2007). Their occurrence is most likely along the west coast of South Africa and is primarily associated with cooler temperatures (Fig. 3). Our results predict that IndoPacific bottlenose dolphins and Indo-Pacific humpback dolphins occur along the entire South African coastline, but with a higher probability along the east and south coats. This is contrary to the literature, which states that they should only occur in warmer waters, predominantly along the east and south coasts (Findlay et al. 1992, Best 2007). Our data show that common dolphins, false killer whales, killer whales and Risso's dolphins are widely distributed within the first half of the South African EEZ. Their distribution, which is driven by a variety of environmental predictors within the EEZ, is similar to what is stated in the literature (e.g. Findlay et al. 1992, Best 2007). The literature suggests that these species have a wide distribution throughout the South African EEZ, with the southern bottlenose whale occurring in deeper offshore waters.

\subsection{Model performance}

The high AUC and TSS scores indicated that the ensemble modelling forecast method accurately defined the predicted likelihood of occurrence for the 9 odontocete species. By using an ensemble modelling method, errors and discrepancies associated with a single model can be limited by using more than one set of initial conditions, classes and parameters to build the model (Thuiller et al. 2009, Breiner et al. 2015, Shabani et al. 2016, Zanardo et al. 2017). Several studies (e.g. Thuiller et al. 2009, Breiner et al. 2015, Shabani et al. 2016, Zanardo et al. 2017) have addressed these issues by comparing single-model results with ensemble model results, and suggested, as did our results, that ensemble models produce more accurate and robust results for species distribution modelling.

All 9 odontocete species had TSS and AUC scores $>0.90$, indicating an excellent discriminatory ability (Pennino et al. 2017, Pereira et al. 2018). TSS scores, although lower in our results, have better model accuracy evaluation for species where there are no true absences (Allouche et al. 2006, Ruete \& Leynaud 2015, Shabani et al. 2016). This is because the TSS method of evaluation is insensitive and independent 
of prevalence, meaning it is able to calculate the percentage of accurately predicted presences and absences (Allouche et al. 2006, Ruete \& Leynaud 2015, Shabani et al. 2016). On the other hand, the AUC method only evaluates sensitivity (predicted presences) and not the specificity (predicted absences) of the model (Allouche et al. 2006, Ruete \& Leynaud 2015, Shabani et al. 2016).

\subsection{Predicted odontocete distributions}

In South Africa, the warm waters of the Agulhas Current and the cold waters of the Benguela Current create a gradient of temperatures providing suitable habitats to cold- and warm-water species (Findlay et al. 1992, Best 2007). The literature indicates that dusky and Heaviside's dolphins occur in cooler west coast waters, no farther east than False Bay and Cape Point, respectively. However, our results indicate that these 2 dolphins can occur farther east, which could be due to the incorporation of records of vagrants into the models. Despite the authenticity of these records, they can still play a large role in shaping predicted distributions, especially if the number of records is low (Guisan et al. 2017). Li \& Wang (2013) indicated that GBM models are more robust when dealing with outliers, such as sightings of vagrants, than other models. The coefficient of variance for dusky dolphins is as high as 0.50 farther offshore and to the east of Cape Point. This suggests that the models for this species did not agree as much with the predictions in these areas compared to the distribution along the west coast close to shore. This, combined with the inclusion of vagrant records, could explain why the model-predicted range limit is farther east than the literature suggests (Findlay et al. 1992, Best 2007).

Results from the predicted distribution of IndoPacific humpback dolphins and Indo-Pacific bottlenose dolphins at a $90 \%$ level of occurrence show that they are likely to occur predominantly along the east and south coast of South Africa. Their predicted distribution is very patchy and could be related to the limited presence data available for both species, resulting in the poor predictive ability of the ensemble models. The literature suggests that both of these species occur in warmer waters, inshore of the Agulhas Current, with their most westerly distribution limits being west of Cape Agulhas (Best 2007, Vermeulen et al. 2018). Our results do indicate this, but because bathymetry was the variable that primarily described their distribution, there are a few small pockets of predicted distribution for both species farther up the west coast, past False Bay. Also, the coefficient of variance for these species along the west coast is high, suggesting that the models in this area did not agree with the predictions. For this error to be eliminated, more presence points for each species would provide the model with more information to better predict their habitat. For Indo-Pacific humpback dolphins there were 25 presence points and for Indo-Pacific bottlenose dolphins there were 58 presence points. A study by Virgili et al. (2018) recommend a minimum of 50 points as a conservative figure. Our results suggest that for Indo-Pacific bottlenose dolphins, 58 presence points was still not adequate to suitably predict their distribution.

Dusky, Heaviside's, Indo-Pacific bottlenose and common dolphins are predicted to occur coastally, with dusky dolphins occurring quite far offshore on the shelf edge. Our results support the literature (Best 2007) confirming that all 4 species are coastally distributed, with the occasional dusky dolphin sighting in waters more than $2000 \mathrm{~m}$ deep on the shelf and shelf edge (Best 2007).

According to the literature, the other 5 species are pelagic in nature, with only killer whales having a more cosmopolitan distribution and coming closer to shore (Findlay et al. 1992). Our data show that killer whales occur throughout the EEZ, but mostly along the continental shelf and slope, which is also true for Risso's dolphins. Generally, false killer whales prefer waters of between 300 and $3000 \mathrm{~m}$, with occasional incursions into shallower waters (Findlay et al. 1992, Best 2007). Our results indicate that there is a $90 \%$ likelihood of false killer whales occurring along the east coast on the shelf edge, around the western Cape and just offshore off the west coast. The results for these 3 species show that they occur much closer to shore, with very little prediction towards the outer edge of the EEZ. These predicted occurrences could be because of observation bias, induced by very few sightings towards the outer edge of the EEZ. Southern bottlenose whales (Findlay et al. 1992, Best 2007) and common dolphins are also thought to occur throughout the EEZ in deeper waters and more pelagic areas (Best 2007). Our results indicate that southern bottlenose whales prefer warmer offshore waters of the east coast, just off the shelf edge, whereas common dolphins are concentrated around the Agulhas Bank, preferring waters less than $850 \mathrm{~m}$ deep. Again, observation bias could have played a role in restricting the predicted distribution of these cetaceans. The coefficient of variance for killer whales and Risso's dolphins is higher than 0.25 
towards the outer more offshore area of the EEZ, suggesting that the predictions in this area compared to the area closer to shore did not comply with the models.

\subsection{MPAs and management implications}

According to our model, less than $5 \%$ of the preferred habitats of the 9 odontocete species are protected by the established MPAs, with the exception of the Indo-Pacific bottlenose dolphin $(14 \%)$ and Indo-Pacific Humpback dolphin (13\%). However, the additional approved MPAs increased the level of protection of all species (Fig. 5). Results from this study indicate that there are certain areas and MPAs in South Africa's EEZ with a high prediction of likely occurrence for a number of species.

The east coast continental slope within the Natal bioregion is one such area and has a high predicted occurrence $(90 \%)$ of southern bottlenose whales, killer whales, false killer whales and Risso's dolphins. In this region, the shelf is narrow, the slope is steep, and the Agulhas Current is warm and fast moving (Griffiths et al. 2010). Even though the Agulhas Current is thought to be nutrient poor (Griffiths et al. 2010), slopes have been found to interact with upand downwelling, influencing cetacean prey availability (Breen et al. 2016). This habitat type provides the ideal environment for cephalopods (Breen et al. 2016), the remains of which have been found in the stomach contents of all 4 species (Best 2007). Until recently there were no MPAs in this offshore region. With the approval of the new MPAs, there are now 3 MPAs protecting parts of this continental shelf edge and consequently a part of the preferred habitat for these 4 species.

Another area of high diversity is the Agulhas Bank and South-western Cape bioregion, where common dolphins, killer whales, false killer whales, Risso's dolphins, Indo-Pacific humpback dolphins and IndoPacific bottlenose dolphins are all likely to occur. Indo-Pacific bottlenose dolphins and Indo-Pacific humpback dolphins are likely to occur more coastally, whereas the other 4 species occur coastally as well as along the shelf. In this region, there is an overlap between the warm Agulhas Current and the cold Benguela Current, creating eddies and nutrient rich areas of high upwelling along the shelf (Griffiths et al. 2010). There are 11 coastal MPAs in these 2 bioregions, which are only able to protect the coastally predicted habitat of these species (Fig. 1). Since the addition of the approved MPAs, offshore protection has increased, protecting wider habitat variability and species (Fig. 1).

The nutrient-rich west coast of South Africa is driven by 2 elements: firstly, local weather patterns, which drive the inshore upwelling of the cold Benguela Current, and secondly, the offshore Benguela Current, which is more sluggish than the Agulhas Current but creates upwelling and forms part of the South Atlantic Subtropical Gyre (Griffiths et al. 2010). Our results predict that this area is the likely habitat of dusky, Heaviside's and common dolphins and false killer whales occurring inshore and killer whales and Risso's dolphins occurring offshore. Until the new MPAs came into effect, there was very little protection along the west coast (Fig. 1). With the addition of the new MPAs, a greater area of habitat is now protected, especially for the more offshore species (Fig. 1).

The Indo-Pacific humpback dolphin is the only endangered odontocete species in South Africa (Vermeulen et al. 2018). The results from our study indicate that the coastal east and south coast MPAs (Fig. 1) are likely to protect this species, and therefore emphasis should be placed on managing these areas. As Indo-Pacific humpback dolphins are coastal, like Indo-Pacific bottlenose dolphins, they are more susceptible to anthropogenic activities, such as environmental and noise pollution, fisheries and bather protection nets (Vermeulen et al. 2018). For this reason, no-take MPAs will provide the most protection to this species, where anthropogenic activities are monitored and limited.

This study shows that MPAs can only protect a small percentage of odontocete habitat. Even though a large percentage of Indo-Pacific humpback dolphin and Indo-Pacific bottlenose dolphin habitat is protected by MPAs in South Africa, these dolphins and all other investigated species are still susceptible to anthropogenic activities around the MPAs. As these MPAs were not initially designed to protect odontocete species, much of their critical habitats may be located outside of these MPAs. This is where important marine mammal areas (IMMAs) can play a role.

IMMAs are based on the 'important bird areas' concept, where all marine mammals on the International Union for the Conservation of Nature (IUCN) Red List of Threatened Species must be considered, and areas that are important for their conservation must be identified (Corrigan et al. 2014). This study can help in that process by identifying areas where there is a high likelihood of predicted occurrence for these 9 species. Recently South African delegates identified 3 IMMAs for the West Indian Ocean coast 
(IUCN Marine Mammal Protected Areas Task Force 2019). One of the IMMAs, specifically related to odontocete species, included the entire coastline of South Africa in the Indian Ocean to protect IndoPacific humpback dolphins (IUCN Marine Mammal Protected Areas Task Force 2019). These IMMAs, although not subject to the same governance of MPAs, can aid in ecosystem-based management of the oceans, providing protection to cetaceans.

\subsection{Limitations and recommendations}

As with all models, there are documented limitations that need to be taken into consideration when interpreting the results. In this study, we used opportunistic, scientific and historical data, all of which have known spatial and temporal discrepancies (Redfern et al. 2006, Torres et al. 2013, Breen et al. 2016). For example, collecting scientific data either by aircraft or by boat is expensive and usually conducted over small areas close to shore. Historical whaling data and opportunistic data may be subjected to misidentification, location bias and a general lack of absence data (Redfern et al. 2006). To account for some of these limitations, we combined datasets (Table 1), increasing the amount of data to ensure a better model outcome (e.g. Torres et al. 2013, Breen et al. 2016). To address observation bias and a lack of absences specifically, previous studies randomly selected pseudo-absence points within an environmental envelope (Phillips et al. 2009, BarbetMassin et al. 2012). Here, we employed the same strategy to address model limitations, but remain aware of the assumptions introduced into the models.

Our results show that using these methods to supplement data deficiency and thus reduce model prediction error does not always work. Indo-Pacific bottlenose dolphins, Indo-Pacific humpback dolphins and false killer whales exhibited poor predicted occurrence (even though the ensemble model evaluation TSS scores were high, i.e. 0.90 for all 3 species) when compared with their occurrence recorded in the literature (e.g. Best 2007). To improve the ensemble model's predictive ability, more data are required to provide better correlations between presence data and predictor variables (Redfern et al. 2006). Previous studies have also shown that cetaceans with clearly defined environmental limitations, such as dusky and Heaviside's dolphins, provide more accurate predicted distributions when compared to more pelagic species, like southern bottlenose whales, Risso's dolphins and false killer whales (Virgili et al.
2018). Our data indicate that the predicted distribution of these pelagic species is not as widespread throughout South Africa's EEZ as literature has indicated it should be (Findlay et al. 1992, Best 2007).

In our results, the percentage of MPA protection for Indo-Pacific bottlenose dolphins and Indo-Pacific humpback dolphins is under-estimated, as their occurrence along the south and east coasts is very patchy. For the more pelagic species (killer whales, false killer whales, Southern bottlenose whales, Risso's dolphins and common dolphins), protection from the proposed MPAs also appears to be underestimated. Therefore, careful interpretation of predicted distribution, along with a deep understanding of cetacean habitat requirements from current and past literature should be taken into account before any management decisions are formulated.

When looking at the $90 \%$ predicted occurrence (Fig. 6) of species like Risso's dolphins, killer whales and false killer whales, there are high densities of predicted occurrence close to Cape Town and Durban. In these cases, observation bias may have played a role, as densities are high closer to these cities and not many are located offshore. According to Best (2007), these species should have a cosmopolitan range, occurring throughout South Africa's EEZ. The larger populations of these cities equate to more sightings, which may have influenced the models. Fithian et al. (2015) conducted a study to try and correct for observation bias by pooling presence-only and presenceabsence data over many species to estimate bias and improve extrapolation of presence-only data.

To improve these models, we suggest 3 interventions. Firstly, more data need to be collected through platforms of opportunity (i.e. seismic surveys and fishing vessels), scientific surveys and/or collaborations to ensure better correlation between predictor variables and species. Secondly, another modelling approach, such as the ensemble model technique employed by Breiner et al. (2015) using only a few predictor variables at a time, should be tested on these data. A modelling approach like that of Fithian et al. (2015) could also be adopted to remove observation bias. Finally, the scale at which the data are modelled should be carefully selected, depending upon the management requirements in question. Mannocci et al. (2017) described in detail scale selection based on 3 categories of temporal resolution. These include instantaneous (in close proximity to the animal at that specific time), contemporaneous (the environment state within a specific time window, a period of up to months) and climatological (long-term temporal resolution, a period of years). 


\subsection{Conclusions}

This study shows that using an ensemble model as a method to predict the likelihood of occurrence for rare and data-deficient species provides useful baseline knowledge on odontocete species within South Africa's MPAs and EEZ. Species occurrence data from citizen science, opportunistic platforms and historical records enabled us to model the distribution of 9 odontocete species, indicating that this kind of data can be used to improve the scientific knowledge about data-deficient species. Results from this study provide baseline data on preferred habitat types for 9 odontocete species and the environmental factors that drive their distribution. Such baseline data will aid in marine spatial planning and the management of these species. The data will provide the necessary information to aid in the EMP process, as well as to identify areas rich in biodiversity. The preservation of biodiversity in South Africa is mandated by the CBD, of which South Africa is a member state. Our results highlight the lack of habitat protection for these cetaceans by the current largely inshore MPAs. This study emphasises the value of a more representative MPA network encompassing not only coastal, but also offshore habitats. With rising anthropogenic activity resulting from ocean economy expansion, it is imperative that informed decisionmaking processes are used to ensure sustainable and equitable ecosystems-based solutions to management challenges.

Acknowledgements. We thank Nan Rice and all members of the public who collected the incidental sightings records. We acknowledge all those marine mammal observers and passive acoustic monitors who collected the offshore data and the Petroleum Agency of South Africa for being helpful and for releasing their data to us. We thank Mark Robertson for his advice using the BIOMOD2 package and distribution modelling tips. Tom Purdon is thanked for editing and checking grammar.

\section{LITERATURE CITED}

Agardy T, di Sciara GN, Christie P (2011) Mind the gap: addressing the shortcomings of marine protected areas through large scale marine spatial planning. Mar Policy 35:226-232

Allouche O, Tsoar A, Kadmon R (2006) Assessing the accuracy of species distribution models: prevalence, kappa and the true skill statistic (TSS). J Appl Ecol 43: 1223-1232

* Barbet-Massin M, Jiguet F, Albert CH, Thuiller W (2012) Selecting pseudo-absences for species distribution models: how, where and how many? Methods Ecol Evol 3: 327-338
Best PB (2007) Whales and dolphins of the southern African subregion. Cambridge University Press, Cambridge

*Been P, Brown S, Reid D, Rogan E (2016) Modelling cetacean distribution and mapping overlap with fisheries in the northeast Atlantic. Ocean Coast Manag 134: 140-149

Breiner FT, Guisan A, Bergamini A, Nobis MP (2015) Overcoming limitations of modelling rare species by using ensembles of small models. Methods Ecol Evol 6: 1210-1218

CBD (Convention on Biological Diversity) (2010) United Nations Convention on Biological Diversity Conference of the Parties 10 Decision X/2. Strategic Plan for Biodiversity 2011-2020 and the Aichi biodiversity targets. https://www.cbd.int/decision/cop/?id=12268

CBD (2012) COP 10 Decision X/29. Marine and coastal biodiversity. https://www.cbd.int/doc/decisions/cop-10/cop10-dec-29-en.pdf

Coetzee BWT, Robertson MP, Erasmus BFN, Van Rensburg BJ, Thuiller W (2009) Ensemble models predict Important Bird Areas in southern Africa will become less effective for conserving endemic birds under climate change. Glob Ecol Biogeogr 18:701-710

Corrigan CM, Ardron JA, Comeros-Raynal MT, Hoyt E, Di Sciara GN, Carpenter KE (2014) Developing important marine mammal area criteria: learning from ecologically or biologically significant areas and key biodiversity areas. Aquat Conserv 24:166-183

Cutler DR, Edwards TC Jr, Beard KH, Cutler A, Hess KT, Gibson J, Lawler JJ (2007) Random forests for classification in ecology. Ecology 88:2783-2792

* De'ath G, Fabricius KE (2000) Classification and regression trees: a powerful yet simple technique for ecological data analysis. Ecology 81:3178-3192

* Edgar GJ, Stuart-Smith RD, Willis TJ, Kininmonth S and others (2014) Global conservation outcomes depend on marine protected areas with five key features. Nature 506: 216-220

* Elith J, Leathwick JR, Hastie T (2008) A working guide to boosted regression trees. J Anim Ecol 77:802-813

ESRI (Environmental Systems Research Institute) (2011) ArcGIS Desktop: release 10.3. Environmental Systems Research Institute, Redlands, CA

Fernandez E, Lellouche JM (2018) Global Ocean Physical Reanalysis product (Version 4) set. EU Copernicus Marine Service Information. http://resources.marine. copernicus.eu/documents/PUM/CMEMS-GLO-PUM-001030.pdf

Findlay KP (1989) The distribution of cetaceans off the coast of South Africa and South West Africa / Namibia. MSc thesis, University of Pretoria

Findlay K (2018) Operation Phakisa and unlocking South Africa's ocean economy. J Indian Ocean Reg 14:248-254

Findlay KP, Best PB, Ross GJB, Cockcroft VG (1992) The distribution of small odontocete cetaceans off the coasts of South Africa and Namibia. S Afr J Mar Sci 12:237-270

Fithian W, Elith J, Hastie T, Keith DA (2015) Bias correction in species distribution models: pooling survey and collection data for multiple species. Methods Ecol Evol 6: $424-438$

Forney KA, Ferguson MC, Becker EA, Fiedler PC and others (2012) Habitat-based spatial models of cetacean density in the eastern Pacific Ocean. Endang Species Res 16: 113-133

Fox J, Weisberg S (2011) An R companion to applied regres- 
sion, 2nd edn. SAGE Publications, Thousand Oaks, CA Griffiths CL, Robinson TB, Lange L, Mead A (2010) Marine biodiversity in South Africa: an evaluation of current states of knowledge. PLOS ONE 5:e12008

Guisan A, Thuiller W, Zimmermann NE (2017) Habitat suitability and distribution models. Cambridge University Press, Cambridge

Halpin PN, Read AJ, Fujioka E, Best BD and others (2009) OBIS-SEAMAP: the world data center for marine mammal, sea bird, and sea turtle distributions. Oceanography 22:104-115

Harris J, Livingstone T, Phadima J, Sink K, Fasheun TA, Boyd A, Mfeka X (2014) Phakisa Initiative: fast-tracking establishment of an effective and representative network of Marine Protected Areas for South Africa. Symposium of Contemporary Conservation Practice, Howick, KwaZulu-Natal

Hastie T, Tibshirani R, Buja A (1994) Flexible discriminant analysis by optimal scoring. J Am Stat Assoc 89: 1255-1270

Hijmans RJ (2015) Raster: geographic analysis and modeling with raster data. R Package version 2.5-2. https://cran. r-project.org/package=raster

Hoyt E (2012) Marine protected areas for whales, dolphins and porpoises: a worldwide handbook for cetacean habitat conservation. Routledge, London

IUCN Marine Mammal Protected Areas Task Force (2019) Preliminary Report of the Fifth IMMA Workshop: Regional Workshop for Western Indian Ocean and Arabian Seas, Salalah, Sultanate of Oman, 4-8 March 2019

Kadmon R, Farber O, Danin A (2004) Effect of roadside bias on the accuracy of predictive maps produced by bioclimatic models. Ecol Appl 14:401-413

Li X, Wang Y (2013) Applying various algorithms for species distribution modelling. Integr Zool 8:124-135

Lombard AT, Strauss T, Harris J, Sink K, Attwood C, Hutchings L (2004) South African National Spatial Biodiversity Assessment 2004: Tech Rep. Vol 4: Marine Component. South African National Biodiversity Institute, Pretoria

* Long RD, Charles A, Stephenson RL (2015) Key principles of marine ecosystem-based management. Mar Policy 57: $53-60$

Mannocci L, Boustany AM, Roberts JJ, Palacios DM and others (2017) Temporal resolutions in species distribution models of highly mobile marine animals: recommendations for ecologists and managers. Divers Distrib 23: 1098-1109

McQuaid CD (2010) Marine connectivity: timing is everything. Curr Biol 20:R938-R940

* Navarro-Cerrillo RM, Duque-Lazo J, Manzanedo RD, Palacios-Rodriguez G (2017) Climate change may threaten the southernmost Pinus nigra subsp. salzmannii (Dunal) Franco populations: an ensemble niche-based approach. iForest Biogeosci For 11:396-405

* Nowacek DP, Bröker K, Donovan G, Gailey G and others (2013) Responsible practices for minimizing and monitoring environmental impacts of marine seismic surveys with an emphasis on marine mammals. Aquat Mamm 39: 356-377

* O'Brien RM (2007) A caution regarding rules of thumb for variance inflation factors. Qual Quant 41:673-690

Pennino MG, Mérigot B, Fonseca VP, Monni V, Rotta A (2017) Habitat modeling for cetacean management: spatial distribution in the southern Pelagos Sanctuary (Mediterranean Sea). Deep Sea Res II 141:203-211
Pereira HM, Ferrier S, Walters M, Geller GN and others (2013) Essential biodiversity variables. Science 339:277-278

* Pereira JM, Krüger L, Oliveira N, Meirinho A, Silva A, Ramos JA, Paiva VH (2018) Using a multi-model ensemble forecasting approach to identify key marine protected areas for seabirds in the Portuguese coast. Ocean Coast Manag 153:98-107

* Phillips SJ, Dudík M, Elith J, Graham CH, Lehmann A, Leathwick J, Ferrier S (2009) Sample selection bias and presence-only distribution models: implications for background and pseudo-absence data. Ecol Appl 19:181-197

QGIS Development Team (2018) QGIS Geographic Information System. Open Source Geospatial Foundation Project. http://qgis.osgeo.org

R Core Team (2019) R: a language and environment for statistical computing. R Foundation for Statistical Computing, Vienna. Version 3.6.1

Redfern JV, Ferguson MC, Becker EA, Hyrenbach KD and others (2006) Techniques for cetacean-habitat modeling. Mar Ecol Prog Ser 310:271-295

* Roberts KE, Valkan RS, Cook CN (2018) Measuring progress in marine protection: a new set of metrics to evaluate the strength of marine protected area networks. Biol Conserv 219:20-27

RSA (Republic of South Africa) (1994) National Environmental Management: Biodiversity Act 10 of 1994. Government Notice 700 in South African Government Gazette 26436. Government Printer, Pretoria

RSA (1998) Marine Living Resources Act 18 of 1998. Government Notice 747 in South African Government Gazette18930. Regulations in terms of the Marine Living Resources Act, 1998. Government Printer, Pretoria

RSA (2001) Marine Living Resources Act 18 of 1998. Government Notice 473 in South African Government Gazette 22335. Declaration of area as a marine protected area. Government Printer, Pretoria

RSA (2014) National Environmental Management Act 107 of 1998. Government Notice 982 in South African Government Gazette 38282. Environmental impact assessment regulations. Government Printer, Pretoria

RSA (2015) Mineral and Petroleum Resources Development Act 28 of 2002. Government Notice 466 in South African Government Gazette 38855. Regulation for petroleum exploration and production. Government Printer, Pretoria

RSA (2016) National Environmental Management: Protected Areas Act 57 of 2003. Government Notice 608 in South African Government Gazette 39646. Draft Notice declaring 22 newly proposed MPAs. Government Printer, Pretoria

RSA (2019) National Environmental Management: Protected Areas Act 57 of 2003. Government Notice 757-776 in South African Government Gazette 42487. Notice declaring 20 new marine protected areas. Government Printer, Pretoria

Ruete A, Leynaud GC (2015) Goal-oriented evaluation of species distribution models' accuracy and precision: True Skill Statistic profile and uncertainty maps. PeerJ PrePrints 3:e1208v1, https://doi.org/10.7287/peerj.pre prints.1208v1

SANBI (South African National Biodiversity Institute) (2004) NSBA marine bioregions. http://bgis.sanbi.org/Spatial Dataset/Detail/173 (accessed 4 September 2017)

SANBI (2011) NBA 2011 Marine Protected Areas. http:// bgis.sanbi.org/SpatialDataset/Detail/413 (accessed 4 September 2017) 
Sbrocco EH, Barber PH (2013) MARSPEC: ocean climate layers for marine spatial ecology. Ecology 94:979

Senay SD, Worner SP, Ikeda T (2013) Novel three-step pseudo-absence selection technique for improved species distribution modelling. PLOS ONE 8:e71218

Shabani F, Kumar L, Ahmadi M (2016) A comparison of absolute performance of different correlative and mechanistic species distribution models in an independent area. Ecol Evol 6:5973-5986

Sink K (2016) The Marine Protected Areas debate: implications for the proposed Phakisa Marine Protected Areas Network. S Afr J Sci 112:a0197

Stock A, Micheli F (2016) Effects of model assumptions and data quality on spatial cumulative human impact assessments. Glob Ecol Biogeogr 25:1321-1332

Thomas HL, Macsharry B, Morgan L, Kingston N, Moffitt R, Stanwell-Smith D, Wood L (2014) Evaluating official marine protected area coverage for Aichi Target 11: appraising the data and methods that define our progress. Aquat Conserv 24:8-23

Thuiller W, Richardson DM, Pysek P, Midgley GF, Hughes GO, Rouget M (2005) Niche-based modelling as a tool for predicting the risk of alien plant invasions at a global scale. Glob Change Biol 11:2234-2250

Thuiller W, Lafourcade B, Engler R, Araújo MB (2009) BIOMOD - a platform for ensemble forecasting of species distributions. Ecography 32:369-373

Torres LG, Smith TD, Sutton P, MacDiarmid A, Bannister J,

Editorial responsibility: Peter Corkeron, Woods Hole, Massachusetts, USA
Miyashita T (2013) From exploitation to conservation: Habitat models using whaling data predict distribution patterns and threat exposure of an endangered whale. Divers Distrib 19:1138-1152

* van Wyk JA (2015) Defining the blue economy as a South African strategic priority: toward a sustainable 10th province? J Indian Ocean Reg 11:153-169

*Vermeulen E, Bouveroux T, Plön S, Atkins S and others (2018) Indian Ocean humpback dolphin (Sousa plumbea) movement patterns along the South African coast. Aquat Conserv 28:231-240

* Virgili A, Authier M, Monestiez P, Ridoux V (2018) How many sightings to model rare marine species distributions. PLOS ONE 13:e0193231

Volpe G, Santoleri SC, Forneris V, Brando V, Garnesson P, Taylor B, Grant M (2019) Ocean Colour set. EU Copernicus Marine Service Information. http://marine.copernicus. eu/services-portfolio/access-to-products/?option=com_ csw\&view=details\&product_id=OCEANCOLOUR_GLO_ CHL_L4_REP_OBSERVATIONS_009_082

WWisz MS, Guisan A (2009) Do pseudo-absence selection strategies influence species distribution models and their predictions? An information-theoretic approach based on simulated data. BMC Ecol 9:8

₹ Zanardo N, Parra GJ, Passadore C, Möller LM (2017) Ensemble modelling of southern Australian bottlenose dolphin Tursiops sp. distribution reveals important habitats and their potential ecological function. Mar Ecol Prog Ser 569:253-266

Submitted: May 14, 2019; Accepted: November 5, 2019 Proofs received from author(s): December 21, 2019 